Preprints of the

Max Planck Institute for

Research on Collective Goods

Bonn 2008/39

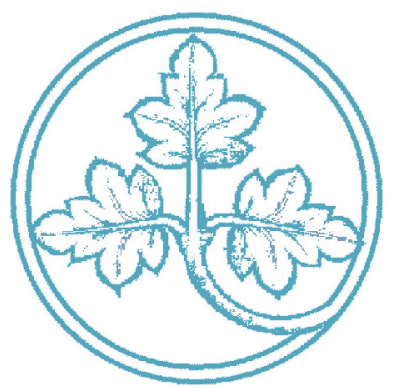

A unified approach to the revelation of public goods preferences and to optimal income taxation

Felix Bierbrauer

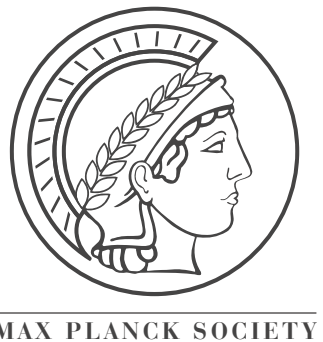




\section{A unified approach to the revelation of public goods preferences and to optimal income taxation}

Felix Bierbrauer

October 2008 


\title{
A unified approach to the revelation of public goods preferences and to optimal income taxation
}

\author{
Felix Bierbrauer* \\ Max Planck Institute, Bonn, Germany
}

October 30, 2008

\begin{abstract}
We study a large economy model in which individuals have private information about their productive abilities and their preferences for public goods. A mechanism design approach is used to characterize implementable tax and expenditure policies. A robustness requirement in the sense of Bergemann and Morris (2005) yields individual incentive compatibility constraints that are equivalent to those in the theory of optimal income taxation in the tradition of Mirrlees (1971). Adding a requirement of coalition-proofness yields a set of collective incentive conditions which are akin those in the literature on public goods provision under private information on preferences, in the tradition of Clarke (1971) and Groves (1973).
\end{abstract}

Keywords: Optimal Taxation, Public goods provision, Revelation of Preferences, Robust Mechanism Design.

JEL: D71, D82, H21, H41

\footnotetext{
*I am very grateful for comments by Martin Hellwig and John Weymark. I also benefited from conversations with Ernesto Crivelli, Christoph Engel, Mike Golosov, Marco Sahm, and Thomas Mertens. Earlier versions of this paper were presented at MIT, the University of Bonn, the Max Planck Institute for Research on Collective Goods, the Public Economic Theory conference 2007 in Nashville, and the EEA-ESEM meeting 2007 in Budapest. I am grateful for the hospitality of MIT where part of this research was conducted.
} 


\section{Introduction}

This paper provides a characterization of tax and expenditure policies that can be implemented in a model in which tax revenues are used to cover the cost of public goods provision and in which individuals have private information about their preferences for public goods and about their productive abilities. It combines two different strands of the literature in public economics that traditionally have been separated: the theory of optimal income taxation in the tradition of Mirrlees (1971), and the theory of public goods provision under asymmetric information in the tradition of Clarke (1971) and Groves (1973).

The theory of optimal income taxation is concerned with the characterization of a welfare maximizing tax systems under the assumption that individual labor supply is not exogenous but a function of the tax system itself. This literature mostly ignores public expenditures and assumes that the government has an exogenously given revenue requirement. ${ }^{1}$

The literature on public goods provision focusses on the characterization of a surplus maximizing rule for the provision and financing of public goods under the assumption that individuals have private information on their preferences. ${ }^{2}$ This literature, however, disregards the production side of the economy and the tax system as an alternative source of public goods finance.

A joint treatment of optimal taxation and preference revelation is difficult for two reasons. First, the combination of private information about productive abilities and of private information about public goods preferences gives rise to a multi-dimensional mechanism design problem. ${ }^{3}$ Second, the models that are used in the theory of optimal taxation and the theory of public goods provision under asymmetric information are very different. While the former studies a large economy model in which each individual acts as a "price-taker" in the sense that the own behavior neither affects aggregate tax revenue nor public spending, the latter studies a finite economy in which each individual has a direct impact on the supply of public goods.

The contribution of this paper is to link these two different strands of the literatures. It is based on a large economy model with endogenous production, as is the theory of optimal taxation. The analysis of admissible tax and expenditure policies is complicated by the fact that the social benefit from public goods provision is a priori unknown. This implies that the policy maker needs to acquire information on the distribution of

\footnotetext{
${ }^{1}$ The papers that include public goods assume that the social benefit from public goods provision is common knowledge, so that the problem of preference elicitation is moot; see, Boadway and Keen (1993), Gahvari (2006), Kaplow (2006) or Hellwig (2004).

${ }^{2}$ Early contributions ask whether efficiency is possible given private information on preferences, Green and Laffont (1977) or d'Aspremont and Gérard-Varet (1979). The more recent literature includes participation constraints, Mailath and Postlewaite (1990), Hellwig (2003) or Neeman (2004).

${ }^{3}$ The literature refers to such problems also as multi-dimensional screening problems; see Rochet and Choné (1998) and Armstrong and Rochet (1999) for a theoretical treatment and Cremer et al. (2001) and Beaudry et al. (2008) for applications to the theory of optimal taxation.
} 
preferences; e.g., he needs to learn whether many or only few individuals have a high valuation of a public good.

However, this problem of preference elicitation may be considered trivial. In a large economy, a single individual's valuation has no influence on the social benefit from public goods provision, so that a single individual's communication of public goods preferences does not affect the supply of public goods. But if no individual can influence public goods provision anyway, then individuals may as well the truth. According to this view, preference elicitation is a trivial problem in a large economy.

With an appeal to real-world political decision making, this conclusion seems to be overly optimistic. If one thinks about the role of political parties and special interest groups, the assumption that individuals with common interests may try to induce policies that are favorable to them seems more plausible than the alternative view that the problem of preference revelation is trivial provided that the number of individuals is sufficiently large. To articulate this concern in a model of optimal income taxation, this paper relies on the solution concept of a coalition-proof equilibrium. It is based on the assumption that like-minded individuals can coordinate their communication of public goods preferences. If a sufficiently large number of individuals departs from truth-telling, the policy maker will end up with a wrong perception of the social benefits from public goods provision and the supply of public goods will be manipulated. A coalition-proof equilibrium requires that there is no group of individuals who can benefit from such a joint lie about their public goods preferences.

The main result of the paper is to provide a characterization of tax and expenditure policies that are implementable as a coalition-proof equilibrium and that are robust in the sense of Bergemann and Morris (2005), i.e., whose implementability does not require specific assumptions on individuals' probabilistic beliefs about the characteristics of other individuals. In particular, we will provide conditions such that the implementability of a policy rule can be reduced to the following two conditions. First, individuals do not benefit from a false declaration of productive abilities. These constraints are equivalent to those in the theory of optimal income taxation developed by Mirrlees (1971). Second, groups of individuals do not benefit from a joint lie about their public goods preferences. This latter requirement gives rise to inequality constraints which are mathematically equivalent to those in Clarke (1971) and Groves (1973). Here, however, they have a political economy interpretation because they refer to the possibility of manipulative collective actions.

In the remainder of the introduction, I provide a sketch of the formal arguments. There is a large number of individuals. Each individual consumes a public and a private good and supplies labor. Utility functions are assumed to be additively separable. An individual's valuation of the public good is increasing in a taste parameter, and an individual's disutility of labor supply is decreasing in a productivity parameter. There is a finite set of possible taste parameters and a finite set of possible productivity levels. Individuals have private information on their productivity and their taste parameter. 
At an aggregate level, there is no uncertainty about the cross-section distribution of abilities; e.g., if there are three possible productivity levels, this means that the population shares of high-skilled, medium-skilled and low-skilled individuals are common knowledge. By contrast, there is uncertainty about the joint distribution of taste parameters and skill levels. Formally, there is a random state of the economy which specifies, for each skill level, a distribution of taste parameters. For instance, with three possible productivity levels and two possible taste parameters a state of the economy lists the fraction of low-skilled individuals with a high taste parameter, the fraction of medium-skilled individuals with a high taste parameter and the fraction of high-skilled individuals with a high taste parameter.

The analysis is based on a mechanism design approach. A mechanism is used to implement a social choice function which consists of a provision rule for public goods and an allocation rule for private goods. The provision rule specifies, for each state of the economy, how much of a public good is provided. The private goods allocation rule specifies a consumption level and an output requirement for individuals as a function of their productivity level, their taste parameter, and the state of the economy.

The set of implementable social choice functions typically depends on the equilibrium concept that is used. A widely-used one is Bayes-Nash equilibrium which is based on the assumption that there is a common prior probability distribution over individual characteristics and that an individual's beliefs are obtained by conditioning this common prior on the individual's private information. Given these beliefs, individual actions are required to be maximizing expected utility. A problem with this solution concept is its dependence on the specification of individual beliefs. The set of implementable social choice functions varies with the common prior that is put into the model. Given that such assumptions about individual beliefs are difficult to defend, the resulting notion of implementability is problematic. To avoid these issues, we will use a notion of robust implementability that has been introduced by Bergemann and Morris (2005).

In a companion paper, Bierbrauer (2008b), we have shown that robust implementability as a Nash equilibrium gives rise to incentive compatibility constraints that are equivalent to those in the theory of optimal income taxation. ${ }^{4}$ This paper adds the requirement that these Nash-equilibria are coalition-proof and derives an additional set of constraints, referred to as collective incentive compatibility constraints.

Coalition formation is modelled as follows. Individuals may jointly manipulate their announcements to a mechanism designer. We follow Laffont and Martimort (1997, 2000) in that we assume that these individuals face an own mechanism design problem. ${ }^{5}$ Hence, a manipulation mechanism must satisfy incentive compatibility constraints which ensure that deviating individuals reveal their characteristics truthfully

\footnotetext{
${ }^{4}$ In particular, consumption levels and output requirements are only a function of productive abilities; i.e., individuals who differ only in their public goods preferences receive the same consumption level and have to provide the same output. Incentive compatibility holds if and only if individuals prefer their own consumption-output bundle over the ones of individuals with different ability levels.

${ }^{5}$ Laffont and Martimort $(1997,2000)$ study a model with two agents who might engage in collusion. This paper extends their approach to an economy with a continuum of individuals.
} 
to a fictitious coalition organizer and participation constraints which ensure that the deviating individuals do indeed benefit from the manipulation. A social choice function is said to be collectively incentive compatible if it leaves no scope for such collective manipulation mechanisms. ${ }^{6}$

It is shown that the collective incentive compatibility constraints only need to address the communication of public goods preferences. Since the cross-section distribution of abilities is commonly known, the policy maker can prevent individuals from a false collective communication of productive abilities by making the outcome that is induced by such a joint deviation sufficiently unattractive. By contrast, the distribution of preferences is not known and the provision of incentives for a collective revelation of preferences is therefore not trivial.

The final part of the paper analyzes collective incentive compatibility under the assumption that the state of the economy is observable but not verifiable. In the literature, such environments are also known as complete information environments. We show show that collective incentive compatibility in all complete information environments is weaker than robust collective incentive compatibility which requires that there is no scope for collective manipulations whatever the probabilistic beliefs of individuals about the state of the economy are. ${ }^{7}$ Robust collective incentive compatibility is a very restrictive concept. For instance, joint manipulations by individuals who oppose public goods provision and by individuals who benefit from public goods provision can restrict the set of implementable social choice functions. However, such manipulations are themselves not robust with respect to the specification of beliefs; e.g., if we change the probability distribution over the possible states of the economy in such a way that a manipulation mechanism becomes more attractive for those who want a public good to be provided, we reach a point where those who are harmed by the provision of the public good are no longer willing to participate. The focus on complete information environments excludes manipulations which are viable only with specific beliefs and implies that aligned preferences are the only rationale for joint manipulations of individuals.

Given the focus on complete information environments, we study the possibility to "aggregate" collective incentive compatibility conditions. In particular, we provide conditions such that the collective incentive constraints which exclude manipulations by individuals who have the same productivity level (but possibly different public goods preferences) can be analyzed as if their was a fictitious "representative agent" who is affected by the income tax system in exactly the same way as these individuals and who announces his own public goods preferences. With this characterization we can show that the collective incentive compatibility conditions are very similar to the in-

\footnotetext{
${ }^{6}$ The requirement that the organization of a manipulation must be internally incentive compatible distinguishes the approach of Laffont and Martimort (1997, 2000) from those of alternative authors. For instance, Olszewski (2004) assumes that a group manipulation is possible as soon as all individuals in the group are willing to participate.

${ }^{7} \mathrm{By}$ contrast, if coalition-proofness is not imposed, these two notions are equivalent, see Ledyard (1978) and Bergemann and Morris (2005).
} 
centive constraints in the literature on public goods provision in the tradition of Clarke (1971) and Groves (1973). In particular, we provide conditions under which a Groves mechanism implements a surplus maximizing public goods provision level as a dominant strategy equilibrium in a revelation game that is played by a set of representative agents, one for each possible productivity level.

The general insight from the literature on public goods is that contributions to the cost of public goods provision have to be calibrated to preference intensities to ensure that individuals reveal their preferences. A similar result is obtained in this paper. The collective incentive compatibility constraints imply that two principles have to be satisfied: The first one is "no taxation without representation": If some representative agent has only a small impact on the supply of public goods under the preference revelation mechanism, then his income tax payments must be independent of the supply of public goods. Otherwise he will understate his public goods preference to minimize his contribution to the cost of public goods provision. The second principle is "no representation without taxation": If the income tax payments of some representative agent do not increase in the supply of public goods, then it is not possible to grant him any influence on public good provision. Otherwise he would exaggerate his public goods preferences so that he can free-ride on the tax payments of others.

The remainder of the paper is organized as follows. Section 2 specifies the model and contains a characterization of robust incentive compatibility. In Section 3, we introduce the notion of a coalition-proof equilibrium and characterize implementable social choice functions. This leads to collective incentive compatibility conditions. Section 4 studies implications of collective incentive compatibility constraints for complete information environments. The last section contains concluding remarks. All proofs are in the Appendix.

\section{Model}

\subsection{The environment}

There is a continuum of individuals. Individual $i$ 's preferences are represented by the utility function

$$
U\left(q, c, y, w^{i}, \theta^{i}\right)=v\left(q, \theta^{i}\right)+u\left(c, y, w^{i}\right)
$$

where $q$ is the amount of a public good, $c$ is the consumption of a private good, and $y$ denotes an individual's effective labour supply, or, contribution to the economy's output. The function $u$ is increasing in $c$, decreasing in $y$ and strictly quasiconcave. The function $v$ gives the utility due to public good provision. For a given $\theta^{i}, v$ is twice continuously differentiable with $v_{q}>0$ and $v_{q q} \leq 0$.

$\theta^{i}$ is a taste parameter that affects individual $i$ 's valuation of the public good. We assume that there is a finite ordered set of possible taste parameters $\Theta=\left\{\theta_{1}, \ldots, \theta_{m}\right\}$ 
and that the marginal utility $v_{q}$ from public good provision is increasing in the taste parameter, $v_{q}\left(q, \theta_{l}\right)<v_{q}\left(q, \theta_{l+1}\right)$. Hence, individuals with a larger taste parameter benefit more from increased public good provision.

$w^{i}$ is a skill or productivity parameter that affects individual $i$ 's disutility of contributing to the economy's output. There is a finite ordered set of possible skill levels $W=$ $\left\{w_{1}, \ldots, w_{n}\right\}$. Indifference curves in a $y-c$-diagram satisfy the single crossing property, i.e., for any given $y$ and $c$, and every $k$,

$$
-\frac{u_{y}\left(c, y, w_{k}\right)}{u_{c}\left(c, y, w_{k}\right)}>-\frac{u_{y}\left(c, y, w_{k+1}\right)}{u_{c}\left(c, y, w_{k+1}\right)} .
$$

Less productive individuals need to exert more effort to produce a given output and hence need more compensation for an increased output requirement.

Individuals are privately informed about their taste parameter and about their skill level. At an aggregate level there is no uncertainty about the cross-section distribution of skill parameters. By contrast, the cross-section distribution of public goods preferences is taken to be a random quantity. More specifically, we impose the following assumptions.

First, there is a commonly known cross-section distribution $f=\left(f_{1}, \ldots, f_{n}\right)$ of skill levels, where $f_{k}$ denotes the fraction of individuals with $w^{i}=w_{k} .{ }^{8}$ This assumption is typically made in the literature on optimal income taxation in the tradition of Mirrlees (1971). It will prove convenient for our purposes because it implies that the economy's resource constraint is not subject to aggregate uncertainty.

Second, the joint cross-section distribution of skill levels and taste parameters is taken to be the realization of a random variable which takes values in a set $S$. A typical element $s \in S$ is referred to as a state of the economy and written as $s=\left(s_{1}, \ldots, s_{n}\right)$, where $s_{k}=\left(s_{k 1}, \ldots, s_{k m}\right)$ is the distribution of taste parameters among individuals with skill level $w_{k}$, i.e., $s_{k l}$ is the fraction of individuals with $\theta^{i}=\theta_{l}$ among those with $w^{i}=w_{k}$. We write $S_{k}$ for the set of possible distributions of taste parameters among individuals with skill level $S_{k}$.

The desirability of public good provision will typically depend on the state $s$. Consider two states $s$ and $s^{\prime}$ such that, for each $k, s_{k}^{\prime}$ first order stochastically dominates $s_{k}$. Hence, in state $s^{\prime}$ more individuals have a high valuation of the public good than in state $s$ so that a welfare maximizing policy rule will be such that in state $s^{\prime}$ more of the public good is provided than in stats $s$.

A social choice function formalizes the dependence of outcomes on the state of the economy. It consists of a provision rule for the public good $q: s \mapsto q(s)$ that specifies for each state $s$ how much of the public good is provided, and a pair of functions $c:(s, w, \theta) \mapsto c(s, w, \theta)$ and $y:(s, w, \theta) \mapsto y(s, w, \theta)$, which determine for each state,

\footnotetext{
${ }^{8}$ Upon invoking a law of large numbers for large economies we can interpret $f_{k}$ both as the ex ante probability that any given individual has skill parameter $w_{k}$, and as the population share of individuals with this skill parameter. For details see Al-Najjar (2004), or Judd (1985a).
} 
each skill level, and each taste parameter a consumption level and an output requirement, respectively. A social choice function is said to be feasible, if for every $s$,

$$
\sum_{k=1}^{n} f_{k} \sum_{l=1}^{m}\left(y\left(s, w_{k}, \theta_{l}\right)-c\left(s, w_{k}, \theta_{l}\right)\right) s_{k l} \geq r(q(s)),
$$

where $r$ is an increasing and convex cost function which captures the resource requirement of public good provision.

This specification restricts attention to social choice functions that are anonymous in the following sense: for a given state $s$, two individuals who have the same taste parameter and the same skill level receive the same private goods consumption and have the same output requirement. Also, a permutation of individual characteristics which leaves the joint cross-section distribution of public goods preferences and skill levels unaffected does neither affect the decision on public goods provision nor, for given $(w, \theta)$, the corresponding consumption level and output requirement. ${ }^{9}$

\subsection{Robust Mechanism Design}

We seek to characterize social choice functions can be made the equilibrium allocation of a game of incomplete information in which individuals have information about their own characteristics but lack information about the characteristics of others and about the state $s$ of the economy. Moreover, in order to avoid specific assumptions about individual beliefs, we will use the notion of robust implementability that has been introduced by Bergemann and Morris (2005). Following their approach, we will first define what it means to implement a social choice function for a given specification of beliefs and then characterize the social choice functions that are robustly implementable, i.e., that can be implemented whatever those beliefs are.

An individual is henceforth characterized by a preference parameter, a productivity level, beliefs about the distribution of these characteristics in the economy and beliefs about the beliefs of other individuals. Following Bergemann and Morris (2005) we summarize these data in a type space $\mathcal{T}:=[T, w, \theta, \pi]$, where $T$ is the set of "abstract" types, $w: t \mapsto w(t)$ is a mapping that specifies the skill level of an individual with type $t$. Likewise, the mapping $\theta: t \mapsto \theta(t)$ gives type $t$ 's taste parameter. For brevity, we refer to the pair $(w(t), \theta(t))$ as the payoff type of type $t$. The function $\pi: t \mapsto \pi(t)$ specifies the beliefs of an individual of type $t$ with respect to the cross-section distribution of types. Let $\phi$ be a typical element of the set of probability distributions on $T, \Delta_{T}$, and $\phi(\mathcal{T})$ be the cross-section distribution of types associated with type space $\mathcal{T}$, then $\pi(t)[X]$ is the probability that a type $t$ individual assigns to the event " $\phi(\mathcal{T})$ belongs to a subset $X$ of $\Delta_{T}$ ".

The beliefs $\pi$ determine both an individuals beliefs about the payoff types of other individuals and about the beliefs of other individuals. To illustrate this let $\phi^{1}$ be the

\footnotetext{
${ }^{9}$ Guesnerie (1995) refers to these properties as recipient anonymity and anonymity in influence, respectively.
} 
marginal cross-sections distribution of payoff types that is associated with a given cross section distribution of types $\phi$ and let $\Delta_{W \times \Theta}$ be the set of probability distributions over $W \times \Theta$. The probability that a type $t$ individual assigns to the event " $\phi{ }^{1}$ belongs to a subset $Y$ of $\Delta_{W \times \Theta}$ " is given by $\int_{\left\{\phi \in \Delta_{T} \mid \phi^{1} \in Y\right\}} d \pi(t)$. In a similar way, we can derive a type $t$ individual's beliefs about the beliefs of other individuals from $\pi(t)$.

A given type space $\mathcal{T}$ is associated with a joint cross-section distribution of taste parameters and skill levels that we denote by $s(\mathcal{T})$. In particular, two type spaces $\mathcal{T}$ and $\mathcal{T}^{\prime}$ may give rise to the same cross-section distribution of payoff types, $s(\mathcal{T})=s\left(\mathcal{T}^{\prime}\right)$, but differ in the specification of individual beliefs so that $\phi(\mathcal{T}) \neq \phi\left(\mathcal{T}^{\prime}\right)$.

Given the restriction to anonymous social choice functions, we limit attention to social choice functions that can be implemented by means of an anonymous allocation mechanism, i.e., a mechanism whose outcome is left unaffected by a permutation of individual actions. ${ }^{10}$ Formally, an anonymous allocation mechanism $M=(A, Q, C, Y)$ specifies an action set $A$ and a collection of functions, where $Q: \alpha \mapsto Q(\alpha)$ gives the level of public good provision as a function of the cross-section distribution of actions $\alpha$, and the functions $C:(\alpha, a) \mapsto C(\alpha, a)$ and $Y:(\alpha, a) \mapsto Y(\alpha, a)$ specify a consumption level and an output requirement as a function of an individual's message $a$ and of the distribution of messages $\alpha$.

A strategy in the game induced by $M$ is a function $\sigma: T \rightarrow A$ that specifies an action for each type of individual. We denote by $\alpha(\phi, \sigma)$ the cross-section distribution of actions that is induced by $\sigma$ if the cross-section distribution of types is $\phi$.

Given an allocation mechanism $M$ and a type space $\mathcal{T}$, we say that the strategy $\sigma^{*}: T \rightarrow A$ is an interim Nash equilibrium if, for all $t \in T$, and all $a \in A$,

$$
\begin{aligned}
& \int_{\Delta_{T}} \tilde{U}\left(\alpha\left(\phi(\mathcal{T}), \sigma^{*}\right), \sigma^{*}(t), w(t), \theta(t)\right) d \pi(t) \\
& \geq \int_{\Delta_{T}} \tilde{U}\left(\alpha\left(\phi(\mathcal{T}), \sigma^{*}\right), a, w(t), \theta(t)\right) d \pi(t),
\end{aligned}
$$

where

$$
\begin{aligned}
& \tilde{U}\left(\alpha\left(\phi(\mathcal{T}), \sigma^{*}\right), a, w(t), \theta(t)\right) \\
& :=U\left(Q\left(\left(\alpha\left(\phi(\mathcal{T}), \sigma^{*}\right)\right), C\left(\alpha\left(\phi(\mathcal{T}), \sigma^{*}\right), a\right), Y\left(\alpha\left(\phi(\mathcal{T}), \sigma^{*}\right), a\right), w(t), \theta(t)\right)\right.
\end{aligned}
$$

is a shorthand notation for the utility that a type $t$ individual realizes under mechanism $M$ from choosing action $a$ given that all other individuals follow strategy $\sigma^{*}$ and the cross-section distribution of types equals $\phi(\mathcal{T})$.

The large economy specification implies that the action chosen by a single individual can not affect the cross-section distribution of actions. This explains why, in the above equilibrium condition, the term $\phi(\mathcal{T})$ appears both on the left-hand side and on the right-hand side.

A social choice function $(q, c, y)$ is said to be implementable on a type space $\mathcal{T}$, if there is some mechanism $M$ such that the equilibrium allocation of the mechanism is equal

\footnotetext{
${ }^{10}$ For a more extensive discussion of anonymous games, see Kalai (2004).
} 
to the outcome that is stipulated by the social choice function for this type space. Formally, the mechanism $M$ is said to implement the social choice function $(q, c, y)$ on type space $\mathcal{T}$, if $\sigma^{*}: T \rightarrow A$ is an in interim Nash equilibrium strategy for the game induced by $M$ on type space $\mathcal{T}$, and moreover

$$
Q\left(\alpha\left(\phi(\mathcal{T}), \sigma^{*}\right)\right)=q(s(\mathcal{T}))
$$

and, for all $t$,

$$
C\left(\alpha\left(\phi(\mathcal{T}), \sigma^{*}\right), \sigma^{*}(t)\right)=c(s(\mathcal{T}), w(t), \theta(t))
$$

and

$$
Y\left(\alpha\left(\phi(\mathcal{T}), \sigma^{*}\right), \sigma^{*}(t)\right)=y(s(\mathcal{T}), w(t), \theta(t))
$$

A social choice function is said to be robustly implementable if there is a mechanism $M$ and a strategy $\sigma^{*}$ such that (i) $\sigma^{*}: T \rightarrow A$ is an interim Nash equilibrium strategy for the game induced by $M$ on every type space, and (ii) conditions (2)-(4) hold on every type space.

This notion of robust implementability differs slightly from the one used by Bergemann and Morris (2005), who allow the mechanism that implements the social choice function to depend on the type space, i.e., a social choice function is robustly implementable in the sense of Bergemann and Morris (2005) if, for every type space $\mathcal{T}$, there is a mechanism $M(\mathcal{T})$ that implements the social choice function on this type space.

We prefer a notion of robustness that differs from the one due to Bergemann and Morris (2005) because the mechanism designer and also the individuals do not know the type space. The mechanism designer's problem is to learn what the type space is. Hence, he can not rely on a mechanism that presupposes that the type space is known. Also, it seems natural to assume that individuals follow the same strategy on every type space. Given that individuals know their types but not the type space, the action that they choose can depend on the former but not on the latter. ${ }^{11}$

The following Proposition provides a characterization of robustly implementable social choice functions.

Proposition 1 A social choice function $(q, c, y)$ is robustly implementable if and only if it satisfies the following individual incentive compatibility constraints: For every $s \in S$ and every $(w, \theta) \in W \times \Theta$,

$$
U(q(s), c(s, w, \theta), y(s, w, \theta), w, \theta) \geq U(q(s), c(s, \hat{w}, \hat{\theta}), y(s, \hat{w}, \hat{\theta}), w, \theta),
$$

for every $(\hat{w}, \hat{\theta}) \in W \times \Theta$.

\footnotetext{
${ }^{11}$ With the solution concept of an interim Nash equilibrium, this distinction is not essential. Both versions of robust implementability give rise to the same constraints on the set of social choice functions. However, in the next section where the requirement of coalition-proofness is added it makes a difference which notion of robustness is employed.
} 
The proof of Proposition 1 is in the Appendix. To get an intuitive understanding, note first that the Revelation Principle implies that robust implementability can be equivalently defined as follows: a direct mechanism, implements a social choice function in a truthful equilibrium on every type space. Second, individual incentive compatibility, as defined by (5), is equivalent to implementability on a specific class of types spaces, namely those where the beliefs of all individuals assign probability 1 to the event that the cross-section distribution of preferences equals $s$. We refer to such types spaces in the following also as complete information type spaces.

The main step in the proof is to show that implementability on each complete information type space implies implementability on each type space. This follows since the payoff from truth-telling on an arbitrary type space is a convex combination of the payoffs from truth-telling on the set of complete information type spaces. Trivially, if truth-telling is a best response on each complete information type space, then it is also a best response "on average".

\subsection{Implications of individual incentive compatibility}

Given Proposition 1, we limit attention to individually incentive compatible social choice functions. Using that the utility function $U$ is additively separable, the incentive compatibility constraints in (5) can be equivalently written as follows. For every $s \in S$ and every $(w, \theta) \in W \times \Theta$,

$$
u(c(s, w, \theta), y(s, w, \theta), w) \geq u(c(s, \hat{w}, \hat{\theta}), y(s, \hat{w}, \hat{\theta}), w),
$$

for all $(\hat{w}, \hat{\theta})$.

Since the economy is large, the supply of the public good is unaffected by a single individual's behavior. This explains why the public good does not enter the individual incentive compatibility constraints.

It is easily verified that the inequalities in (6) imply that, for every $s$, for every given $w$ and every pair $\theta$ and $\theta^{\prime}$,

$$
u(c(s, w, \theta), y(s, w, \theta), w)=u\left(c\left(s, w, \theta^{\prime}\right), y\left(s, w, \theta^{\prime}\right), w\right) .
$$

This equation says that two individuals who differ only in their taste parameter, derive the same utility from their respective $(c, y)$ combination, in every state $s$. Since two individuals who differ only in their taste parameter have the same ranking of alternative $(c, y)$ bundles, it is impossible to discriminate between them.

Given condition (7), it is without loss of generality to assume that also $c(s, w, \theta)=$ $c\left(s, w, \theta^{\prime}\right)$ and $y(s, w, \theta)=y\left(s, w, \theta^{\prime}\right)$, for every $s, w$, and every pair $\left(\theta, \theta^{\prime}\right) .{ }^{12}$ With some abuse of notation, we denote the consumption level of individuals with skill parameter $w$ in state $s$ by $c(s, w)$ and the corresponding output requirement by $y(s, w)$. We can

\footnotetext{
${ }^{12}$ Any welfare-maximizing social choice function is such that individual utility levels are generated at a minimal resource cost. Hence it must be true that $y(s, w, \theta)-c(s, w, \theta)=y\left(s, w, \theta^{\prime}\right)-c\left(s, w, \theta^{\prime}\right)$. This equality in conjunction with the fact that indifference curves in a $y-c$ diagram are strictly increasing and strictly convex, yields $c(s, w, \theta)=c\left(s, w, \theta^{\prime}\right)$ and $y(s, w, \theta)=y\left(s, w, \theta^{\prime}\right)$.
} 
now write the individual incentive compatibility constraints as follows: for every $s$, every $w$, and every $\hat{w}$,

$$
u(c(s, w), y(s, w), w) \geq u(c(s, \hat{w}), y(s, \hat{w}), w) .
$$

The economy's resource constraint in (1) can be written as, for all $s$,

$$
\sum_{k=1}^{n} f_{k}\left(y\left(s, w_{k}\right)-c\left(s, w_{k}\right)\right) \geq r(q(s)),
$$

As indicated by the inequalities in (8), only private information on skill levels is relevant for individual incentive compatibility. Private information on public goods preferences plays no role. This is a striking difference to the literature on public goods provision in "small" economies in the tradition of Clarke (1971), Groves (1973) or d'Aspremont and Gérard-Varet (1979). In these models, each individual announces a taste parameter and thereby affects how much of a public good is provided. In the given large economy model, no individual has a direct influence on public good provision which implies that individual consumption levels and output requirements can not be made dependent on public goods preferences.

The model derived so far is a straightforward extension of the model of optimal income taxation due to Mirrlees (1971). ${ }^{13}$ A difference is that the present model has aggregate uncertainty so that the optimal policy depends on the state $s$ of the economy. However, if the only constraints that need to be taken into account are those in (9) and (8), this has no bearing on the set of optimal policies. Given that individuals have no impact on public good provision, they also have no reason to hide their true public goods preferences from the policy maker. This implies that the policy maker will get the information on the state of the economy for "free", i.e., without having to provide appropriate incentives for a revelation of public goods preferences. The remaining problem is to determine the optimal tax and expenditure policy for each given state $s$. This policy problem is equivalent to the one that is analyzed in the theory of optimal income taxation.

\section{Collective Incentive Compatibility}

The characterization of individually incentive compatible social choice functions in the preceding section has led to the conclusion that, in a large economy, private information on public goods preferences plays no role. Even if there is uncertainty about the social benefits from public good provision, this uncertainty can be easily resolved because, in a large economy, no individual has a direct influence on the quantity of the public

\footnotetext{
${ }^{13}$ Contributions to the theory of optimal income taxation often use a primal approach which relies on a characterization of social choice functions that can be achieved by means of an income tax system, see Stiglitz (1982), Boadway and Keen (1993), Gahvari (2006), or Hellwig (2007). This yields implementability conditions that, for given $s$, coincide with the constraints in (9) and (8).
} 
good, and hence no individual minds revealing his public goods preference.

This view is somewhat implausible. Every democratic society knows the constant struggle of political parties and all sorts of special interest groups about the desirability of expenditure policies. Hence, in a large economy, individuals undertake collective actions in order to influence the provision of public goods. This suggests that, in addition to individual incentive compatibility constraints which incorporate how individual behavior depends on policy choices, the model should also include collective incentive compatibility constraints which take account of the possibility that individuals may lie collectively about their preferences in order to induce policies that are more favorable to them.

Our approach to coalition formation is as follows: A coalition is a subset of types. Given that, with an anonymous social choice function, an individual's expected payoff depends only on the individual's type, this means that we take aligned preferences to be the rationale for coalition formation.

Coalition formation is an own mechanism design problem which gives rise to its own set of incentive problems. ${ }^{14}$ Formally, a coalition is viewed as a direct mechanism. Individuals with types in $R \subset T$ make a (possibly false) type announcement to a fictitious coalition manager. Incentive compatibility constraints ensure that individuals communicate their types truthfully to the coalition organizer.

Given that individuals reveal their types truthfully to the coalition organizer, the latter can acquire partial information about the state of the world because he can observe the population-shares of all types $t$ in $R$. Given this information, the coalition organizer makes announcements on behalf of the individuals with types in $R$ to the overall mechanism designer. Thereby he can manipulate the policy outcome. The following example illustrates this possibility.

\subsection{An example}

Suppose that there are only two possible skill levels $W=\left\{w_{1}, w_{2}\right\}$, i.e., individuals with $w^{i}=w_{1}$ are low-skilled and individuals with $w^{i}=w_{2}$ are high-skilled. Also suppose that $\Theta=\left\{\theta_{1}, \theta_{2}\right\}$ so that individuals with $\theta^{i}=\theta_{1}$ have a low valuation of the public good and individuals with $\theta^{i}=\theta_{2}$ have a high valuation of the public good.

Suppose that $S=S_{1} \times S_{2}$, and that for each skill level $w_{k}, S_{k}$ consists of two elements, $S_{k}=\left\{s_{k}^{\prime}, s_{k}^{\prime \prime}\right\}$, where $s_{k 1}^{\prime}=\frac{3}{4}$ and $s_{k 1}^{\prime \prime}=\frac{1}{4}$; that is, $s_{k}^{\prime \prime}$ is such that among those individuals with $w^{i}=w_{k}$, many have a high valuation of the public good and $s_{k}^{\prime}$ is such that many have a low valuation of the public good. Depending on the distribution of public goods preferences among the high-skilled and low-skilled, respectively, there are in total four possible states of the economy.

\footnotetext{
${ }^{14}$ This approach to coalition formation has been introduced by Laffont and Martimort (1997, 2000). Our approach is here is more general in the sense that we not only allow for deviations by the "grand coalition" of all agents, bot allow any subset of individuals to deviate.
} 
Suppose, for simplicity, that the overall mechanism is a direct mechanism. ${ }^{15}$ Consider a coalition of low-skilled individuals. If all low-skilled individuals reveal their type to the coalition manager the latter learns whether many or only few low-skilled individuals have a high taste for the public good, i.e., he learns whether the distribution of preferences among the low-skilled equals $s_{1}^{\prime}$ or $s_{1}^{\prime \prime}$. However, he remains ignorant with respect to the distribution of preferences among the high-skilled.

In the following we give an example of a social choice function that can be manipulated by such a coalition. Let

$$
V_{k}(s)=u\left(c\left(s, w_{k}\right), y\left(s, w_{k}\right), w_{k}\right)
$$

be a shorthand notation for the utility that individuals with skill level $w_{k}$ derive from their $c-y$ bundle in state $s=\left(s_{1}, s_{2}\right)$. The payoff of a low-skilled individual with taste parameter $\theta$ in state $s$ can then be written as

$$
v\left(q\left(s_{1}, s_{2}\right), \theta\right)+V_{1}\left(s_{1}, s_{2}\right) .
$$

Now suppose that for all $\theta \in \Theta$ and for all $s_{2}$,

$$
v\left(q\left(s_{1}^{\prime}, s_{2}\right), \theta\right)+V_{1}\left(s_{1}^{\prime}, s_{2}\right)>v\left(q\left(s_{1}^{\prime \prime}, s_{2}\right), \theta\right)+V_{1}\left(s_{1}^{\prime \prime}, s_{2}\right) .
$$

This says that, whatever the preferences of the high-skilled, all low-skilled individuals are better off if the mechanism designer chooses policy under the assumption that only few low-skilled individuals have a high valuation of the public good. Such situations can occur in models in which raising taxes for the public good is more painful for the "poor". Even if they have a high valuation of the public good, they prefer less public spending because the disutility of increased taxation does not compensate for the utility gain from increased public good provision. ${ }^{16}$

Now consider the following manipulation mechanism for low-skilled individuals. Whenever the state of the world is such that $s_{1}=s_{1}^{\prime}$ the coalition organizer reports the characteristics of low-skilled agents truthfully to the overall mechanism. By contrast, if $s_{1}=s_{1}^{\prime \prime}$ he reports the skill-parameters truthfully but reports taste parameters in such a way that the reported profile $\hat{s}_{1}$ satisfies $\hat{s}_{1}=s_{1}^{\prime}$. This manipulation makes all low-skilled individual better off, so that they are happy to participate. Moreover, the coalition mechanism itself is incentive compatible. This follows because the coalition organizer only manipulates taste parameters and individuals are indifferent which taste parameter to announce. Hence, the coalition manager makes a choice from an individual's best response correspondence, which implies that no individual has an incentive to lie to the coalition manager.

\footnotetext{
${ }^{15}$ Below, we prove that the Revelation Principle holds in our model, so that this assumption is without loss of generality.

${ }^{16}$ Bierbrauer (2008a) and Bierbrauer and Sahm (2008) show that Mirrleesian models of optimal nonlinear income taxation may give rise to this constellation.
} 


\subsection{Implementation as a coalition-proof equilibrium}

A manipulation for individuals with types in $R$ is a list of probability distributions $\chi_{R}=\left\{\chi\left(\phi_{R}, t\right)\right\}_{t \in R}$ with support $A$; i.e., $\chi\left(\phi_{R}, t\right)[a]$ is the probability that an individual with type $t$ will choose action $a$, if the cross-section distribution of types in $R$ is given by $\phi_{R}$.

We assume that an individual's action conditional on $\phi_{R}$ and $t$ may be random. However, the distribution of actions that is communicated by the coalition organizer is not. In the example in Subsection 3.1, it may be random for whom the coalition organizer chooses to announce a low taste parameter instead of a high taste parameter. In any case, he chooses a profile of announcements such that $\hat{s}_{1}=s_{1}^{\prime}$ with probability 1 .

Let a mechanism $M=(A, Q, C, Y)$ be given. In the following, we denote by $\alpha\left(\phi, \sigma, \chi_{R}\right)$ the (non-random) distribution of actions that results if the cross-section distribution of types is $\phi$, individuals with types not in $R$ follow a strategy $\sigma$ and individuals with types in $R$ behave according to the manipulation mechanism $\chi_{R}$. With this notation we denote by

$$
\begin{aligned}
& \tilde{U}\left(\alpha\left(\phi, \sigma, \chi_{R}\right), a, w(t), \theta(t)\right) \\
& :=U\left(Q\left(\left(\alpha\left(\phi, \sigma, \chi_{R}\right)\right), C\left(\alpha\left(\phi, \sigma, \chi_{R}\right)\right), a\right), Y\left(\alpha\left(\phi, \sigma, \chi_{R}\right), a\right), w(t), \theta(t)\right)
\end{aligned}
$$

the utility that a type $t$ individual realizes under mechanism $M$ from choosing action $a$ given that the distribution of actions is $\alpha\left(\phi, \sigma, \chi_{R}\right)$. If all individuals follow $\sigma$, i.e., if there is no manipulation, then we denote the payoff by $\tilde{U}(\alpha(\phi, \sigma), a, w(t), \theta(t))$.

Given a type space $\mathcal{T}$, a mechanism $M$, and an interim Nash equilibrium strategy $\sigma^{*}$, we say that manipulation $\chi_{R}$ satisfies the participation constraint, if for all $t \in R$,

$$
\begin{array}{r}
\int_{\Delta_{T}} \int_{A} \tilde{U}\left(\alpha\left(\phi(\mathcal{T}), \sigma^{*}, \chi_{R}\right), a, w(t), \theta(t)\right) d \chi_{R}\left(\phi_{R}(\mathcal{T}), t\right) d \pi(t) \\
>\int_{\Delta_{T}} \tilde{U}\left(\alpha\left(\phi(\mathcal{T}), \sigma^{*}\right), \sigma^{*}(t), w(t), \theta(t)\right) d \pi(t) .
\end{array}
$$

Individuals will only participate in the manipulation mechanism if this leads to a higher expected payoff relative to a situation where all individuals behave according to $\sigma^{*}$, so that the participation constraint has to be satisfied for all types in $R$.

Since the coalition manager has no information about individual characteristics, the manipulation has to be incentive compatible. This has two aspects. First, individuals must prefer revealing their type truthfully to the coalition manger over lying to the coalition manager. Hence, for all $t$ and $t^{\prime}$ in $R$,

$$
\begin{array}{r}
\int_{\Delta_{T}} \int_{A} \tilde{U}\left(\alpha\left(\phi(\mathcal{T}), \sigma^{*}, \chi_{R}\right), a, w(t), \theta(t)\right) d \chi_{R}\left(\phi_{R}(\mathcal{T}), t\right) d \pi(t) \\
\geq \int_{\Delta_{T}} \int_{A} \tilde{U}\left(\alpha\left(\phi(\mathcal{T}), \sigma^{*}, \chi_{R}\right), a, w(t), \theta(t)\right) d \chi_{R}\left(\phi_{R}(\mathcal{T}), t^{\prime}\right) d \pi(t) .
\end{array}
$$

Second, individuals with types in $R$ must prefer communicating with the coalition organizer over communicating directly with the overall mechanism, i.e., for every $t \in R$ 
and every $a^{\prime} \in A$,

$$
\begin{array}{r}
\int_{\Delta_{T}} \int_{A} \tilde{U}\left(\alpha\left(\phi(\mathcal{T}), \sigma^{*}, \chi_{R}\right), a, w(t), \theta(t)\right) d \chi_{R}\left(\phi_{R}(\mathcal{T}), t\right) d \pi(t) \\
\geq \int_{\Delta_{T}} \tilde{U}\left(\alpha\left(\phi(\mathcal{T}), \sigma^{*}, \chi_{R}\right), a^{\prime}, w(t), \theta(t)\right) d \pi(t) .
\end{array}
$$

$\sigma^{*}$ is said to be a coalition-proof interim Nash equilibrium in the game induced by mechanism $M$ on type space $\mathcal{T}$ if it is an interim Nash equilibrium and there is no subset of types $R$ with a manipulation $\chi_{R}$ that is incentive compatible and satisfies the participation constraint. ${ }^{17}$

A social choice function $(q, c, y)$ is said to be implementable as a coalition-proof interim Nash equilibrium on type space $\mathcal{T}$, if there is a mechanism $M$ and a strategy $\sigma^{*}$ such that (i) for the game induced by $M$ on type space $\mathcal{T}, \sigma^{*}$ is a coalition-proof interim Nash equilibrium, and (ii) the equilibrium allocation coincides with the prescription of the social choice function for this type space; i.e., conditions (2)-(4) are satisfied.

This model of coalition formation does not consider the possibility that manipulations may rely on side-payments; e.g., individuals who seek to change the outcome of the mechanism may pay other individuals for modifying their messages. For the notion of collective incentive compatibility that will be derived below in Proposition 3, this is without loss of generality. A discussion of the argument is relegated to the Appendix, see Section A.4.

\subsection{Robust implementability}

It is straightforward to add the requirement of coalition-proofness to the notion of robust implementability that was introduced in Section 2: A social choice function is said to be robustly implementable as a coalition-proof interim Nash equilibrium if there is a mechanism $M$ and a strategy $\sigma^{*}$ such that (i) $\sigma^{*}: T \rightarrow A$ is a coalition-proof interim Nash equilibrium strategy for the game induced by $M$ on every type space and (ii) conditions (2)-(4) hold on every type space.

This solution concept of robust implementability as a coalition-proof interim Nash equilibrium combines the ideas of Laffont and Martimort (1997, 2000), on the one hand, and of Bergemann and Morris (2005), on the other. As Laffont and Martimort, we allow individuals to manipulate the overall allocation mechanism and, moreover, treat coalition formation as an own mechanism design problem that faces participation and incentive compatibility constraints. ${ }^{18}$ This yields a notion of implementability as a coalition-

\footnotetext{
${ }^{17}$ The notion of coalition-proofness by Bernheim et al. (1986) imposes one further requirement: If a coalition $R$ forms, this must not trigger a further deviation by a subset $R^{\prime}$ of $R$, where the latter would again have to pass this test, and so on. With this approach, coalition-proofness does not have a lot of bite. A mechanism designer could then use "off-the-equilibrium-rewards" to destabilize any coalition; that is, he could promise payoffs to subcoalition $R^{\prime}$ - knowing that these payoffs are never realized to eliminate any incentive for individuals in $R$ to deviate.

${ }^{18}$ The framework here is more general in that we allow for coalitions of any size which also implies that the coalition formation is subject to incomplete information about the distribution of characteristics among those individuals who do not participate.
} 
proof equilibrium, for a given environment, and, in particular, for a given specification of individual beliefs. Following Bergemann and Morris, we then add the requirement of robust implementability, i.e., we require that implementation as a coalition-proof equilibrium is possible for every environment and, in particular, for every cross-section distribution of individual beliefs.

Proposition 2 below shows that the requirement of coalition-proofness changes the relationship between social choice functions that are robustly implementable and those that are implementable on every complete information type space. Without coalitionproofness the two are equivalent as follows from Proposition 1. With coalition-proofness, robust implementability implies implementability on every complete information type space but not vice versa.

Proposition 2 Robust implementability of a social choice function as a coalition-proof interim Nash equilibrium implies implementability as a coalition-proof interim Nash equilibrium on every complete information types space. The converse implication does not hold.

The reason that robust implementability as a coalition-proof equilibrium is more restrictive than implementability on every complete information type space is that, with robust implementability, joint manipulations by individuals who have antagonistic preferences may restrict the set of implementable social choice functions. The proof of the Proposition (see the Appendix) is based on an example of a binary public good that is either provided $(q=1)$ or not provided $(q=0)$. In this setting, a joint manipulation by individuals who are harmed by public good provision and by individuals who benefit from public good provision can by supported if we make specific assumptions about individual beliefs. The manipulation works as follows. Those who are harmed by public good provision are willing to make public good provision possible in some state $s^{\prime}$ if they are compensated by non-provision in some other state $s^{\prime \prime}$. Likewise, individuals who benefit from public good provision are willing to block public good provision in some state if this implies that the public good will be provided in some other state. ${ }^{19}$ However, such a manipulation is not robust with the respect to the specification of beliefs. For instance, if all individuals put a lot of probability mass on the true state of the economy being $s^{\prime}$, then individuals who oppose public good provision, will not consider the above manipulation very attractive. Likewise, if individuals assume that the state is almost surely $s^{\prime \prime}$, then individuals who benefit from public good provision will not participate. Consequently, if attention is limited to complete information environments, then coalition-proofness is a less stringent constraint because joint manipulations of types whose preferences are opposed to each other will no longer restrict the set of implementable social choice functions.

\footnotetext{
${ }^{19}$ With a similar logic, one can construct examples such that that individuals who have the same preferences but different beliefs disagree over the attractiveness of a manipulation and hence fail to coordinate.
} 
In the following, we will limit attention to complete information type spaces. The requirement that a social function is implementable on each complete information type space seems reasonable for environments where agents have accurate information about the distribution of preferences. To give an example, suppose that a political decision has to be taken and each party that participates in the decision-making mechanism has a very good sense of the preferences of all other parties. However, while these preferences are known among parties, they are not verifiable: There is nothing that prevents a party from communicating that it does not want a bridge to be built (e.g., in order to limit its contributions to the cost of provision), even if all other parties know that, in fact, the party would be better off otherwise.

In addition, the restriction to complete information type spaces has some further implications that are convenient. First, manipulations will be driven exclusively by aligned preferences. This follows since all individuals have the same beliefs so that preferences are the only source of heterogeneity. In particular, there is no role for manipulations that are viable only because of specific assumptions on the beliefs of individuals. A further advantage is tractability. This will become clear in the subsequent Section where we study the implications or implementability for all complete information environments. Finally, given that implementability on every complete information type space is weaker than the requirement of robust implementability, the constraints that we derive in the following also have to be satisfied with the more demanding solution concept.

The following Proposition characterizes the social choice functions that are implementable as a coalition-proof interim Nash equilibrium on every complete information type space. In particular, it is shown that the requirement of coalition-proofness gives rise to an additional set of constraints that we refer to as collective incentive compatibility constraints.

Proposition 3 The following statements are equivalent.

(a) A social choice function is implementable as a coalition-proof interim Nash equilibrium on every complete information type space

(b) A social choice function is truthfully implementable on every complete information type space, i.e., there is a direct mechanism such that truth-telling is a coalition-proof interim Nash equilibrium on every complete information type space.

(c) A social choice function is individually incentive compatible and satisfies the following collective incentive compatibility constraints: for all $s$, for all $\Gamma \subset$ $\{1, \ldots, n\} \times\{1, \ldots, m\}$ and for all $\hat{s} \in \hat{S}(s, \Gamma)$, there exists $(k, l) \in \Gamma$ such that

$$
v\left(q(s), \theta_{l}\right)+V_{k}(s) \geq v\left(q(\hat{s}), \theta_{l}\right)+V_{k}(\hat{s}),
$$


where $\hat{S}(s, \Gamma) \subset S$ contains the distributions of payoff types that can be induced if starting from $s$, for all types $\left(w_{k}, \theta_{l}\right)$, with $(k, l) \in \Gamma$, the probability mass $s_{k l}$ is reallocated among payoff types $\left(w_{k}^{\prime}, \theta_{l}^{\prime}\right)$ such that $w_{k}=w_{k}^{\prime}$.

The equivalence of statements (a) and (b) establishes that the Revelation Principle holds in our model. If there is a mechanism that implements a social choice function on every complete information type space, then it can also be implemented as truthtelling equilibrium of a direct mechanism; i.e., it is without loss of generality to assume that individuals announce a skill level and a taste parameter and that there must not exist a complete information type space such that individuals have an incentive to manipulate their announcements.

Statement (c) provides us with a characterization of social choice functions that satisfy this property. There must not exist a state $s$ and a set of individuals with an incentive to manipulate the mechanism designer's perception of the state of the economy so that he chooses the outcome intended for state $\hat{s}$. According to (c) it suffices to exclude manipulations which are such that individuals reveal their skills but lie about their taste parameters.

The focus on collective lies about taste parameters arises because of the assumption that the cross-section distribution of skill levels $f$ is not subject to aggregate uncertainty. Hence, any collective lie that involves an announced skill profile that is incompatible with $f$ can be easily deterred by the mechanism designer. Given that deviating individuals must act in accordance with a predetermined marginal distribution of skill levels, it is without loss of generality to assume that collective lies involve only taste parameters.

Moreover, given that only taste parameters are manipulated, the incentive compatibility constraints that a manipulation faces are trivially satisfied. The social choice function treats individuals who differ only in their public goods preferences equally so that the announcement of a false taste parameter is a best response from every individual's perspective. The only constraint that a manipulation mechanism faces is therefore the participation constraint: there must not exist a set of individuals who can benefit from a joint lie about their taste parameters.

The characterization of individual incentive compatibility in Proposition 1 and of collective incentive compatibility in Proposition 3 can be summarized as follows: Individual incentive compatibility refers only to private information about skill levels. Given a decision on public policy, individuals will adjust their behavior to the environment they are facing, i.e., they choose how much to work and how much to consume. Their assessment of the consumption-leisure tradeoff depends only on the skill level. This explains why public goods preferences are irrelevant for individual incentive compatibility.

Collective incentive compatibility addresses only the communication of public goods preferences. Given that the mechanism designer faces uncertainty only about the social benefit from public good provision, but not on the cross-section distribution of skill levels he needs to provide incentives for a collective revelation of preferences but not 
for a collective revelation of productive abilities.

\section{Implications of collective incentive compatibility}

In this section, we study implications of the requirement that a social choice function must be collectively incentive compatible. In particular, we focus on a specific set of manipulations which are such that all participating individuals have the same skill level, but possibly different preferences for the public good. Our main goal is to find conditions such that the set of collective incentive compatibility constraints that are generated by these manipulations can be "aggregated" in the sense that they admit a representation as a single representative individual's incentive constraint. As will become clear, such a characterization makes it possible to relate the collective incentive conditions in this paper very easily to the incentive conditions which ensure a revelation of preferences in the finite economy models that were studied by Clarke (1971), Groves (1973) and their successors.

To exclude manipulations by individuals who have the same skills we focus on the following subset of the collective incentive compatibility constraints that were derived in Proposition 3. For all $s=\left(s_{1}, \ldots, s_{n}\right)$, for all $k \in\{1, \ldots, n\}$, for all $\Gamma_{k} \subset\{1, \ldots, m\}$, and for all $\hat{s}_{k} \in \hat{S}_{k}\left(s_{k}, \Gamma_{k}\right)$, there exists $l \in \Gamma_{k}$ such that

$$
v\left(q\left(s_{k}, s_{-k}\right), \theta_{l}\right)+V_{k}\left(s_{k}, s_{-k}\right) \geq v\left(q\left(\hat{s}_{k}, s_{-k}\right), \theta_{l}\right)+V_{k}\left(\hat{s}_{k}, s_{-k}\right),
$$

where $\hat{S}_{k}\left(s_{k}, \Gamma_{k}\right) \subset S_{k}$ contains the distributions of payoff types among individuals with $w^{i}=w_{k}$ that can be induced if starting from $s_{k}$, for all taste parameters $\theta_{l}$, with $l \in \Gamma_{k}$, the probability mass $s_{k l}$ is reallocated among payoff types $\left(w_{k}^{\prime}, \theta_{l}^{\prime}\right)$ such that $w_{k}=w_{k}^{\prime}$.

We impose the following assumptions. For each skill level $w_{k}$, the set $S_{k}$ contains $m$ elements that are ordered according to first order stochastic dominance; $S_{k}=\left\{s_{k}^{1}, \ldots, s_{k}^{m}\right\}$ where, for any $l, s_{k}^{l+1}$ first order stochastically dominates $s_{k}^{l}$. Moreover, as one moves from $s_{k}^{l}$ to $s_{k}^{l+1}$ the mass of all taste parameters other than $\theta_{l}$ and $\theta_{l+1}$ is unaffected; i.e., the number of individuals with taste parameter $\theta_{l+1}$ is increased at the expense of the number of individuals with taste parameter $\theta_{l}$. These assumptions are imposed in the following without further mention.

Proposition 4 A social choice function satisfies the constraints in (14) if and only for all $k$, for all $s_{-k}$ and for all $l$,

$$
v\left(q\left(s_{k}^{l}, s_{-k}\right), \theta_{l}\right)+V_{k}\left(s_{k}^{l}, s_{-k}\right) \geq v\left(q\left(s_{k}^{l+1}, s_{-k}\right), \theta_{l}\right)+V_{k}\left(s_{k}^{l+1}, s_{-k}\right),
$$

and

$$
v\left(q\left(s_{k}^{l}, s_{-k}\right), \theta_{l}\right)+V_{k}\left(s_{k}^{l}, s_{-k}\right) \geq v\left(q\left(s_{k}^{l-1}, s_{-k}\right), \theta_{l}\right)+V_{k}\left(s_{k}^{l-1}, s_{-k}\right) .
$$

Condition (15) is a local upward incentive compatibility constraint for individuals with

skill level $w_{k}$ and taste parameter $\theta_{l}$. If $s_{k}=s_{k}^{l}$ then a subset of these individuals could 
collectively declare a taste parameter equal to $\theta_{l+1}$ so that the distribution of preferences that is communicated to the mechanism designer equals $\hat{s}_{k}=s_{k}^{l+1}$. The incentive constraint (15) ensures that this is not attractive for these individuals. Similarly, (16) is a local downward incentive compatibility constraint that ensures that these individuals do not understate their preferences. The Proposition shows that these local incentive constraints are sufficient to ensure that the constraints in (14) are satisfied. Hence, if a local deviation violates the participation constraint for individuals with $\theta_{l}$, then the same is true for any deviation. ${ }^{20}$

The incentive conditions in (16) and (15) can be interpreted as referring to a "representative agent" in the following sense: Consider a special version of the above model, so that $s_{k}=s_{k}^{1}$ indicates that all individuals with $w^{i}=w_{k}$ have a taste parameter equal to $\theta_{1}, s_{k}=s_{k}^{2}$ indicates that all individuals with $w^{i}=w_{k}$ have a taste parameter equal to $\theta_{2}$, etc.. Hence, in every state of the economy, all individuals with the same skill level also have the same taste parameter. Now assume that in order to determine $s_{k}$ the policy maker asks a randomly chosen individual with skill level $w_{k}$ to make an announcement about the own taste parameter. This again gives rise to the incentive conditions (16) and (15). These constraints can therefore be interpreted as standard dominant strategy incentive compatibility constraints in a finite model with $n$ representative agents, one for each skill level, who make an announcement about their own taste parameter.

\subsection{Groves mechanisms}

We now discuss the possibility to implement a surplus-maximizing provision rule for the public good subject to the collective incentive compatibility constraints in (16) and (15). The focus on surplus maximization drives the analysis of Clarke-Groves mechanisms in finite economy models. We show below that this analysis can be replicated in this paper's large economy model. Hence, the combination of the individual incentive compatibility constraints in Proposition 1 and the collective incentive compatibility constraints in Proposition 4 is indeed a synthesis of Mirrleesian income taxation and incentives for a revelation of preferences in the sense of Clarke and Groves.

The collective incentive conditions in (16) and (15) are only a subset of all collective incentive compatibility constraints. In particular, the possibility of joint manipulations by individuals of different abilities is left open. However, given that the constraints in Proposition 4 have the same structure as the well-understood dominant strategy individual incentive compatibility conditions in models with finitely many agents, ignoring collective incentive compatibility constraints that involve a coordination of several representative agents is as good or as bad as the focus on individual incentive compatibility in finite economy models. For instance, Crémer (1996) has shown that Groves mechanisms are generally manipulable by coalitions of several agents, even if coalition

\footnotetext{
${ }^{20}$ This follows from standard arguments which exploit the assumption that the marginal utility from public good provision $v_{q}$ increases in the taste parameter. See the Appendix.
} 
formation itself is subject to incentive compatibility conditions.

The surplus maximizing provision level $q^{*}(s)$ is defined by the condition

$$
\left\{q^{*}(s)\right\}:=\operatorname{argmax}_{x \in \mathbb{R}} \sum_{k=1}^{n} f_{k} \sum_{l=1}^{m} s_{k l} v\left(x, \theta_{l}\right)-r(x)
$$

The construction of a Groves mechanism is based on the observations that a surplus maximizing choice of $q$ implies that, for all $k$, for all $s_{-k}$ and for all $s_{k}^{l} \in S_{k}$,

$$
\begin{aligned}
s_{k}^{l} \in \operatorname{argmax}_{s_{k}^{j} \in S_{k}} & \sum_{g \neq k} f_{g} \sum_{h=1}^{m} s_{g h} v\left(q^{*}\left(s_{k}^{j}, s_{-k}\right), \theta_{h}\right) \\
& +f_{k} \sum_{h=1}^{m} s_{k h}^{l} v\left(q^{*}\left(s_{k}^{j}, s_{-k}\right), \theta_{h}\right)-r\left(q^{*}\left(s_{k}^{j}, s_{-k}\right)\right),
\end{aligned}
$$

and that incentive compatibility requires that for all $k$, for all $s_{-k}$ and for all $s_{k}^{l} \in S_{k}$,

$$
s_{k}^{l} \in \operatorname{argmax}_{s_{k}^{j} \in S_{k}} v\left(q^{*}\left(s_{k}^{j}, s_{-k}\right), \theta_{l}\right)+V_{k}\left(s_{k}^{j}, s_{-k}\right) .
$$

A Groves mechanism is based on the idea to choose $V_{k}$ such that two maximization problems are equivalent. This requires that (i) for every $k$, for all $s_{-k}$, for all $s_{k}^{l}$, and for all $s_{k}^{j}$ the objective functions of the maximization problems (17) and (18) are equal,

$$
\begin{aligned}
V_{k}\left(s_{k}^{j}, s_{-k}\right)= & -v\left(q^{*}\left(s_{k}^{j}, s_{-k}\right), \theta_{l}\right)+\sum_{g \neq k} f_{g} \sum_{h=1}^{m} s_{g h} v\left(q^{*}\left(s_{k}^{j}, s_{-k}\right), \theta_{h}\right) \\
& +f_{k} \sum_{h=1}^{m} s_{k h}^{l} v\left(q^{*}\left(s_{k}^{j}, s_{-k}\right), \theta_{h}\right)-r\left(q^{*}\left(s_{k}^{j}, s_{-k}\right)\right)
\end{aligned}
$$

and (ii) that the right-hand side of (19) is independent of $s_{k}^{l}$, the true distribution of preferences among individuals with skill level $w_{k}$.

Generally, it will not be possible to achieve (i) and (ii) simultaneously. However, if we impose the assumptions that skills are uniformly distributed $\left(f_{k}=\frac{1}{n}\right.$, for each $k$ ) and that there is no heterogeneity in public goods preferences among individuals with the same taste parameter (for each $k, s_{k}^{1}=(1,0, \ldots, 0), s_{k}^{2}=(0,1,0, \ldots, 0), \ldots$, $\left.s_{k}^{m}=(0, \ldots, 0,1)\right)$ we have a model that is mathematically identical to a finite economy model. Not surprisingly, this implies that a Groves mechanisms works.

To see this, note first that (17) can now be written as follows: for every $k$, for every $s_{-k}$ and for all $s_{k}^{l}$,

$$
\begin{aligned}
s_{k}^{l} \in \operatorname{argmax}_{s_{k}^{j} \in S_{k}} & \sum_{g \neq k} v\left(q^{*}\left(s_{k}^{j}, s_{-k}\right), \theta\left(s_{g}\right)\right)+v\left(q^{*}\left(s_{k}^{j}, s_{-k}\right), \theta\left(s_{k}^{l}\right)\right) \\
& -n r\left(q^{*}\left(s_{k}^{j}, s_{-k}\right)\right),
\end{aligned}
$$

where $\theta\left(s_{g}\right)$ is the taste parameter of individuals with $w^{i}=w_{g}$ in state $s$. If we now rewrite (19) accordingly, this yields

$$
V_{k}\left(s_{k}^{j}, s_{-k}\right)=\sum_{g \neq k} v\left(q^{*}\left(s_{k}^{j}, s_{-k}\right), \theta\left(s_{g}\right)\right)-n r\left(q^{*}\left(s_{k}^{j}, s_{-k}\right)\right)
$$

which is just the standard definition of a Groves mechanism. The following Proposition summarizes these results. 
Proposition 5 If skills are uniformly distributed and every state $s$ is such that $w^{i}=$ $w^{j}$ implies $\theta^{i}=\theta^{j}$ for every pair of individuals $i$ and $j$, then a Groves mechanism implements the surplus maximizing provision rule $q^{*}$ subject to the collective incentive compatibility constraints (16) and (15).

The Proposition shows that a Groves mechanism can elicit information on public goods preferences and implement the surplus maximizing decision on public good provision. As is well known from the analysis of Groves mechanisms in finite economies, budget balance is typically not possible. ${ }^{21}$ In the model of this paper there is an additional concern, namely whether consumption levels and output requirements can be chosen such that individual incentive compatibility holds. In the following, we discuss the implications of collective incentive compatibility constraints for the analysis of tax systems which, traditionally, has been concerned with government budget constraints and incentive constraints at the individual level.

\subsection{Implications for the analysis of income tax systems}

Collective incentive compatibility imposes constraints on the joint analysis of public goods provision and taxation. We now derive two necessary conditions which describe how taxes of individuals have to vary with the state $s$ of the economy. If these conditions are violated public policy will be manipulated.

By (15) and (16), collective incentive compatibility holds if and only if for all $k$, for all $s_{-k}$ and for all $l<m$,

$$
v_{q}\left(q\left(s_{k}^{l+1}, s_{-k}\right), \theta_{l+1}\right)-v_{q}\left(q\left(s_{k}^{l}, s_{-k}\right), \theta_{l+1}\right) \geq V_{k}\left(s_{k}^{l}, s_{-k}\right)-V_{k}\left(s_{k}^{l+1}, s_{-k}\right),
$$

and

$$
V_{k}\left(s_{k}^{l}, s_{-k}\right)-V_{k}\left(s_{k}^{l+1}, s_{-k}\right) \geq v_{q}\left(q\left(s_{k}^{l+1}, s_{-k}\right), \theta_{l}\right)-v_{q}\left(q\left(s_{k}^{l}, s_{-k}\right), \theta_{l}\right) .
$$

According to (22), the drop in the utility from private goods $V_{k}$ as one moves from $s_{k}^{l}$ to $s_{k}^{l+1}$ must be bounded from above so that individuals with taste parameter $\theta_{l+1}$ are willing to accept this utility loss in exchange for the utility gain that is due to increased public good provision. If this condition was violated then individuals with taste parameter $\theta_{l+1}$ would understate their preferences for the public good.

According to (23), the drop in the utility from private goods must be bounded from below. If this property was violated then the cost of increased public good provision that is born by individuals with taste parameter $\theta_{l}$ is so small that these individuals would exaggerate their public goods preferences.

Adding these inequalities and using the assumption that the marginal utility from public good provision increases in the taste parameter reveals that $q\left(s_{k}^{l}, s_{-k}\right) \leq q\left(s_{k}^{l+1}, s_{-k}\right)$, i.e., if there are ceteris paribus more individuals with a high taste parameter among

\footnotetext{
${ }^{21}$ Green and Laffont (1977) show that this is generally true for any mechanism with a dominant strategy equilibrium that achieves surplus maximization.
} 
those with skill level $w_{k}$, this increases the amount of the public good that is provided. Using (23) this implies that $V_{k}\left(s_{k}^{l}, s_{-k}\right) \geq V_{k}\left(s_{k}^{l+1}, s_{-k}\right)$, if more of the public good is provided this must imply that individuals with skills $w_{k}$ pay more taxes and hence derive a lower utility from private goods. Moreover, (22) and (23) imply that

$$
q\left(s_{k}^{l}, s_{-k}\right)=q\left(s_{k}^{l+1}, s_{-k}\right) \Longleftrightarrow V_{k}\left(s_{k}^{l}, s_{-k}\right)=V_{k}\left(s_{k}^{l+1}, s_{-k}\right) .
$$

The implication $q\left(s_{k}^{l}, s_{-k}\right)=q\left(s_{k}^{l+1}, s_{-k}\right) \Longrightarrow V_{k}\left(s_{k}^{l}, s_{-k}\right)=V_{k}\left(s_{k}^{l+1}, s_{-k}\right)$ can be interpreted as "no taxation without representation", i.e., if a larger willingness to pay for the public good among individuals with skills $w_{k}$ is not reflected by the provision rule $q$, then it is not possible to tax these individuals more heavily. They would never admit a higher valuation of the public good if the only consequence was that they have to pay more taxes. The converse implication reads as "no representation without taxation." If individuals do not pay more taxes as their valuation of the public good goes up, then the provision rule for the public good cannot incorporate this change in preferences. Otherwise, individuals would always exaggerate their preferences for the public good since they do not have to pay for it.

\section{Concluding Remarks}

This paper has derived two sets of incentive conditions for public policy. Individual incentive compatibility takes into account how individuals respond to an income tax system that determines their after-tax income as a function of their labor supply. Collective incentive compatibility incorporates that individuals may lobby for certain expenditure policies and thus addresses the political reactions that may be triggered by the policy mechanism.

The analysis has led to a set of necessary conditions that are implied by the requirement of collective incentive compatibility. If a group of individuals experiences a shift in their public goods preferences such that their willingness to pay for a public good is increased, then it must be true that more of the public good is provided (otherwise these individuals understate their public goods preferences) and that these individuals pay more taxes (otherwise they exaggerate their preferences). More generally speaking, the tax system confronts individuals with prices for public goods. Collective incentive compatibility requires that these prices are set in an "appropriate" manner, namely in such a way that the demand for public goods can be determined.

The present paper has illustrated this logic within the model that is used in the theory of optimal income taxation. However, the same kind of reasoning applies to any model of taxation. To illustrate this, imagine a model of capital taxation in the sense of Chamley (1986) and Judd (1985b). Suppose that this economy converges to a stationary state in which the distribution of public goods preferences is random in each period. Obviously, if individuals who have only capital income never pay taxes in such a long-run equilibrium, then the arguments of this paper imply that it becomes impossible to reflect their preferences when choosing the level of public expenditures. 
Alternatively, if their preferences are to be considered, then people with capital income will have to pay taxes at least in those circumstances where they value the public good rather highly.

\section{References}

Al-Najjar, N. (2004). Aggregation and the law of large numbers in large economies. Games and Economic Behavior, 47:1-35.

Armstrong, A. and Rochet, J. (1999). Multi-dimensional screening: A user's guide. European Economic Review, 43:959-979.

Beaudry, P., Blackorby, C., and Szalay, D. (2008). Taxes and employment subsidies in optimal redistribution programs. American Economic Review, forthcoming.

Bergemann, D. and Morris, S. (2005). Robust mechanism design. Econometrica, 73:1771-1813.

Bernheim, B., Peleg, B., and Whinston, M. (1986). Coalition-proof Nash equilibria I. concepts. Journal of Economic Theory, 42:1-12.

Bierbrauer, F. (2008a). Optimal income taxation and public good provision with endogenous interest groups. Mimeo, Max Planck Institute for Research on Collective Goods, Bonn.

Bierbrauer, F. (2008b). Optimal income taxation, public goods provision and robust mechanism design. Preprint 2008/31, Max Planck Institute for Research on Collective Goods, Bonn.

Bierbrauer, F. and Sahm, M. (2008). Optimal democratic mechanisms for income taxation and public good provision. Preprint 2008/9, Max Planck Institute for Research on Collective Goods, Bonn.

Boadway, R. and Keen, M. (1993). Public goods, self-selection and optimal income taxation. International Economic Review, 34:463-478.

Chamley, C. (1986). Optimal taxation of capital income in general equilibrium with infinite lives. Econometrica, 54:607-622.

Clarke, E. (1971). Multipart pricing of public goods. Public Choice, 11:17-33.

Cremer, H., Pestieau, P., and Rochet, J. (2001). Direct versus indirect taxation: The design of the tax structure revisited. International Economic Review, 42:781-799.

Crémer, J. (1996). Manipulations by coalitions under asymmetric information: The case of Groves mechanisms. Games and Economic Behavior, 13:39-73. 
d'Aspremont, C. and Gérard-Varet, L. (1979). Incentives and incomplete information. Journal of Public Economics, 11:25-45.

Gahvari, F. (2006). On the marginal costs of public funds and the optimal provision of public goods. Journal of Public Economics, 90:1251-1262.

Green, J. and Laffont, J. (1977). Characterization of satisfactory mechanisms for the revelation of preferences for public goods. Econometrica, 45:472-487.

Groves, T. (1973). Incentives in teams. Econometrica, 41:617-663.

Guesnerie, R. (1995). A Contribution to the Pure Theory of Taxation. Cambridge University Press.

Hellwig, M. (2003). Public-good provision with many participants. Review of Economic Studies, 70:589-614.

Hellwig, M. (2004). Optimal income taxation, public goods provision and public-sector pricing: A contribution to the foundations of public economics. Preprint 2004/14, Max Planck Institute for Research on Collective Goods, Bonn.

Hellwig, M. (2007). A contribution to the theory of optimal utilitarian income taxation. Journal of Public Economics, 91:1449-1477.

Judd, K. (1985a). The law of large numbers with a continuum of i.i.d. random variables. Journal of Economic Theory, 35:19-25.

Judd, K. (1985b). Redistributive taxation in a simple perfect foresight model. Journal of Public Economics, 28:59-83.

Kalai, E. (2004). Large robust games. Econometrica, 72:1631-1665.

Kaplow, L. (2006). Public goods and the distribution of income. European Economic Review, 50:1627-1660.

Laffont, J. and Martimort, D. (1997). Collusion under asymmetric information. Econometrica, 65:875-911.

Laffont, J. and Martimort, D. (2000). Mechanism design with collusion and correlation. Econometrica, 68:309-342.

Ledyard, J. (1978). Incentive compatibility and incomplete information. Journal of Economic Theory, 18:171-189.

Mailath, G. and Postlewaite, A. (1990). Asymmetric bargaining procedures with many agents. Review of Economic Studies, 57:351-367.

Mirrlees, J. (1971). An exploration in the theory of optimum income taxation. Review of Economic Studies, 38:175-208. 
Neeman, Z. (2004). The relevance of private information in mechanism design. Journal of Economic Theory, 117:55-77.

Olszewski, W. (2004). Coalition strategy-proof mechanisms for provision of excludable public goods. Games and Economic Behavior, 46:88-114.

Rochet, J. and Choné, P. (1998). Ironing, sweeping, and multidimensional screening. Econometrica, 66:783-826.

Stiglitz, J. (1982). Self-selection and Pareto-efficient taxation. Journal of Public Economics, 17:213-240.

\section{A Appendix}

\section{A.1 Proof of Proposition 1}

The Revelation Principle implies that a social choice function $(q, c, y)$ is implementable as an interim Nash equilibrium by some mechanism $M$ on a given type space $\mathcal{T}$ if and only if it is truthfully implementable, i.e., if and only if their exists a direct mechanism $M^{\prime}$ with an action set $A^{\prime}=T$ and outcome functions $Q^{\prime}: \phi \mapsto Q^{\prime}(\phi), C^{\prime}:(\phi, t) \mapsto C^{\prime}(\phi, t)$, and $Y^{\prime}:(\phi, t) \mapsto Y^{\prime}(\phi, t)$ such that (i) Truth-telling is an interim Nash equilibrium; i.e., for all $t$

$$
t \in \operatorname{argmax}_{t^{\prime} \in T} \int_{\Delta_{T}} U\left(Q^{\prime}(\phi(\mathcal{T})), C^{\prime}\left(\phi(\mathcal{T}), t^{\prime}\right), Y^{\prime}\left(\phi(\mathcal{T}), t^{\prime}\right), w(t), \theta(t)\right) d \pi(t) ;
$$

and (ii) the equilibrium allocation is equal to the social choice function,

$$
Q^{\prime}(\phi(\mathcal{T}))=q(s(\mathcal{T}))
$$

and, for every $t$,

$$
C^{\prime}(\phi(\mathcal{T}), t)=c(s(\mathcal{T}), w(t), \theta(t)) \quad \text { and } \quad Y^{\prime}(\phi(\mathcal{T}), t)=y(s(\mathcal{T}), w(t), \theta(t)) .
$$

We will show that a social choice function is individually incentive compatible if and only if it is truthfully implementable as an interim Nash equilibrium on every extended type space $\mathcal{T}$.

"£": Given an incentive compatible social choice function $(q, c, y)$ and given an extended types space $\mathcal{T}$, construct a direct mechanism $\left(T, Q^{\prime}, C^{\prime}, Y^{\prime}\right)$ such that $(25)$ and (26) hold. We seek to verify that, for every $t$,

$$
\begin{aligned}
t & \in \operatorname{argmax}_{t^{\prime} \in T} \int_{\Delta_{T}} U\left(Q^{\prime}(\phi(\mathcal{T})), C^{\prime}\left(\phi(\mathcal{T}), t^{\prime}\right), Y^{\prime}\left(\phi(\mathcal{T}), t^{\prime}\right), w(t), \theta(t)\right) d \pi(t) \\
& =\operatorname{argmax}_{t^{\prime} \in T} \sum_{s} \hat{\pi}(t)[s] U\left(q(s), c\left(s, w\left(t^{\prime}\right), \theta\left(t^{\prime}\right)\right), y\left(s, w\left(t^{\prime}\right), \theta\left(t^{\prime}\right)\right), w(t), \theta(t)\right),
\end{aligned}
$$

where $\hat{\pi}(t)[s]:=\int_{\left\{\phi \in \Delta_{T} \mid \phi^{1}=s\right\}} d \pi(t)$, and $\phi^{1}$ denotes the marginal cross-section distribution of payoff types associated with $\phi$. Equivalently, for every $t$,

$$
(w(t), \theta(t)) \in \operatorname{argmax}_{\left(w^{\prime}, \theta^{\prime}\right) \in W \times \Theta} \sum_{s} \hat{\pi}(t)[s] U\left(q(s), c\left(s, w^{\prime}, \theta^{\prime}\right), y\left(s, w^{\prime}, \theta^{\prime}\right), w(t), \theta(t)\right) .
$$

This follows from the fact that $(q, c, y)$ is incentive compatible.

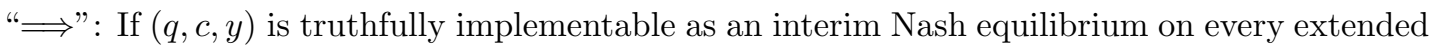
type space, then $(q, c, y)$ is, in particular, truthfully implementable on every complete information type space; i.e., on every type space $\mathcal{T}$ which is such that, for all $t, \hat{\pi}(t)[s]=1$, for some 
given $s$. If a direct mechanism $\left(T, Q^{\prime}, C^{\prime}, Y^{\prime}\right)$ truthfully implements $(q, c, y)$ on such a type space then it must be true that (25) and (26) hold for this type space. Using these conditions to substitute for $Q^{\prime}, C^{\prime}$, and $Y^{\prime}$, the equilibrium conditions in (24) becomes: for all $t$ and all $t^{\prime}$,

$$
\begin{gathered}
U(q(s), c(s, w(t), \theta(t)), y(s, w(t), \theta(t)), w(t), \theta(t)) \geq \\
U\left(q(s), c\left(s, w\left(t^{\prime}\right), \theta\left(t^{\prime}\right)\right), y\left(s, w\left(t^{\prime}\right), \theta\left(t^{\prime}\right)\right), w(t), \theta(t)\right) ;
\end{gathered}
$$

or, equivalently, for all $(w, \theta)$ and $\left(w^{\prime}, \theta^{\prime}\right)$,

$$
U(q(s), c(s, w, \theta), y(s, w, \theta), w, \theta) \geq U\left(q(s), c\left(s, w^{\prime}, \theta^{\prime}\right), y\left(s, w^{\prime}, \theta^{\prime}\right), w, \theta\right) .
$$

Since the choice of $s$ was arbitrary, the latter inequality holds for all $s$. Hence, $(q, c, y)$ is individually incentive compatible.

\section{A.2 Proof of Proposition 2}

Robust implementability as a coalition-proof interim Nash equilibrium implies, be definition, implementability on every complete information type space. It hence remains to be shown that implementability on every complete information type space does not imply robust implementability. This is proven by means of an example.

Suppose that there are two possible skill levels, $W=\left\{w_{1}, w_{2}\right\}$ and three possible taste parameters, $\Theta=\left\{\theta_{1}, \theta_{2}, \theta_{3}\right\}$. Suppose that $S=\left\{s^{\prime}, \bar{s}^{\prime}, s^{\prime \prime}, \bar{s}^{\prime \prime}\right\}$, where

i) $s^{\prime}$ is such that all low-skilled individuals have a low taste parameter, $s_{11}^{\prime}=1$, and all high-skilled individuals have taste parameter $\theta_{2}, s_{22}^{\prime}=1 . \bar{s}^{\prime}$ is such that all low-skilled individuals have a low taste parameter, $s_{13}^{\prime}=1$, and all high-skilled individuals have taste parameter $\theta_{2}, \bar{s}_{22}^{\prime}=1$.

ii) $s^{\prime \prime}$ is such that all low-skilled individuals have taste parameter $\theta_{2}, s_{12}^{\prime \prime}=1$, and all highskilled individuals have a high taste parameter, $s_{23}^{\prime \prime}=1 . \bar{s}^{\prime \prime}$ is such that all low-skilled individuals have taste parameter $\theta_{2}, \bar{s}_{12}^{\prime \prime}=1$, and all high-skilled individuals have a low taste parameter, $\bar{s}_{21}^{\prime \prime}=1$.

Let $(q, c, y)$ be an individually incentive compatible social choice function, which implies that a direct mechanism can implement $(q, c, y)$ as a truthful interim Nash equilibrium on every type space.

We introduce the following notation for the payoffs induced by the social choice function. In state $s^{\prime}$ the payoff of low-skilled individuals with a low taste parameter is $x_{11}^{\prime}$, i.e.

$$
v\left(q\left(s^{\prime}\right), \theta_{1}\right)+V_{1}\left(s^{\prime}\right)=x_{11}^{\prime} .
$$

A low-skilled individual with a high taste parameter would derive utility

$$
v\left(q\left(s^{\prime}\right), \theta_{3}\right)+V_{1}\left(s^{\prime}\right)=x_{13}^{\prime} .
$$

from the outcome prescribed by the social choice function for state $s^{\prime}$. Likewise, we denote the payoff of high-skilled individuals with taste parameter $\theta_{2}$ by $x_{22}^{\prime}$, For state $\bar{s}^{\prime}$ we define $\bar{x}_{11}^{\prime}, \bar{x}_{13}^{\prime \prime}$, $\bar{x}_{22}^{\prime}$ in the same way. The analog definitions apply for states $s^{\prime \prime}$ and $\bar{s}^{\prime \prime}$.

Suppose the payoffs induced by the social choice function are as follows:

i) $x_{11}^{\prime}=\bar{x}_{11}+\epsilon$, i.e., low-skilled individuals with a low taste parameter prefer the outcome for state $s^{\prime}$ over the outcome for state $\bar{s}^{\prime} . x_{22}^{\prime}=\bar{x}_{22}^{\prime}-2 \epsilon$ so that high-skilled individuals prefer the outcome for state $\bar{s}^{\prime}$ over the outcome for state $s^{\prime}$. 
ii) Analogously, $x_{23}^{\prime \prime}=\bar{x}_{23}^{\prime \prime}+\epsilon$ and $x_{12}^{\prime \prime}=\bar{x}_{12}^{\prime \prime}-2 \epsilon$.

iii) $x_{11}^{\prime} \in \operatorname{argmax}\left\{x_{11}^{\prime}, \bar{x}_{11}^{\prime}, x_{11}^{\prime \prime}, \bar{x}_{11}^{\prime \prime}\right\}$, and $\bar{x}_{13}^{\prime} \in \operatorname{argmax}\left\{x_{13}^{\prime}, \bar{x}_{13}^{\prime}, x_{13}^{\prime \prime}, \bar{x}_{13}^{\prime \prime}\right\}$.

iv) $x_{23}^{\prime \prime} \in \operatorname{argmax}\left\{x_{23}^{\prime}, \bar{x}_{23}^{\prime}, x_{23}^{\prime \prime}, \bar{x}_{23}^{\prime \prime}\right\}$, and $\bar{x}_{21}^{\prime \prime} \in \operatorname{argmax}\left\{x_{21}^{\prime}, \bar{x}_{21}^{\prime}, x_{21}^{\prime \prime}, \bar{x}_{21}^{\prime \prime}\right\}$.

Step 1. We will now verify that this social choice function can be implemented as a coalitionproof interim Nash equilibrium on every complete information type space. Consider a direct mechanism which achieves the social choice function, i.e., which is such that for all $s \in S$ and for all of the corresponding complete information type spaces, conditions (2)-(4) are satisfied. We show that truth-telling is coalition-proof on every complete information type space.

Construct the direct mechanism such that, whenever the cross-section distribution of type announcements is incompatible with any of the four complete information type spaces, then all individuals receive a very low payoff. This deters any manipulation that leads away from the set of outcomes prescribed by the social choice function. This implies, in particular, that we can assume that all individuals reveal their skill levels truthfully. Given the assumption that there is a commonly known distribution $f$ of skill levels, a collective manipulation of skill levels yields a bad payoff and does not satisfy the participation constraints. Also, given any distribution of announcements that is consistent with a complete information type space for one of the possible states in $S$, due to individual incentive compatibility, revealing one's skill level is a best response. Hence, in the following we limit attention to manipulations that involve only lies about taste parameters.

Consider state $s^{\prime}$ and a corresponding complete information type space. A coalition that consists only of high-skilled has no manipulation that satisfies the participation constraint. Given that low-skilled individuals reveal their characteristics, any such manipulation leads away from the outcomes prescribed by the social choice function. Given that high-skilled individuals reveal their characteristics truthfully, a coalition that consists only of low-skilled individuals could induce the outcome for state $\bar{s}^{\prime}$. Since $x_{11}^{\prime}=\bar{x}_{11}^{\prime}+\epsilon$ this is incompatible with the participation constraint. A manipulation by high-skilled and low-skilled individuals can induce the outcome for any state $s \in S$. However, since $x_{11}^{\prime} \in \operatorname{argmax}\left\{x_{11}^{\prime}, \bar{x}_{11}^{\prime}, x_{11}^{\prime \prime}, \bar{x}_{11}^{\prime \prime}\right\}$ none of these manipulations satisfies the participation constraint for low-skilled individuals.

A similar argument can be made for any alternative state $s \in S$. Hence, the social choice function is implementable as a coalition-proof equilibrium on every complete information type space.

Step 2. We will now show that the social choice function $(q, c, y)$ specified above is not implementable on a type space $\mathcal{T}^{\prime}$ such that the cross-section distribution of payoffs is given by $s\left(\mathcal{T}^{\prime}\right)=s^{\prime}$ and the beliefs of all individuals assign probability $\frac{1}{2}$ to the state of the economy being $s^{\prime}$ and also probability $\frac{1}{2}$ to the state being $s^{\prime \prime}$.

Suppose to the contrary that there is a mechanism $M=(A, Q, C, Y)$ and a strategy $\sigma^{*}$ that implement $(q, c, y)$ on each complete information type space and on $\mathcal{T}^{\prime}$. Consider a manipulation by the grand coalition of all agents. Given that the manipulation is incentive compatible, this implies that the coalition organizer will learn the true state $s$ of the economy. Now suppose that the coalition organizer chooses the actions for the overall mechanism in the following way:

i) In states $\bar{s}^{\prime}$ and $\bar{s}^{\prime \prime}$ the outcome remains unmanipulated, i.e., for an individual that has announced type $t$, the coalition organizer's choice is $\sigma^{*}(t)$.

ii) In state $s^{\prime}$ the coalition organizer chooses for each $t$ with $(w(t), \theta(t))=\left(w_{1}, \theta_{1}\right)$, an action $\sigma^{*}\left(t^{\prime}\right)$ where $t^{\prime}$ is such that $\left(w\left(t^{\prime}\right), \theta\left(t^{\prime}\right)\right)=\left(w_{1}, \theta_{3}\right)$. For each $t$ with $(w(t), \theta(t))=\left(w_{2}, \theta_{2}\right)$ he chooses the action $\sigma^{*}(t)$. 
iii) In state $s^{\prime \prime}$ the coalition organizer chooses for each $t$ with $(w(t), \theta(t))=\left(w_{2}, \theta_{3}\right)$, an action $\sigma^{*}\left(t^{\prime}\right)$ where $t^{\prime}$ is such that $\left(w\left(t^{\prime}\right), \theta\left(t^{\prime}\right)\right)=\left(w_{2}, \theta_{1}\right)$. For each $t$ with $(w(t), \theta(t))=\left(w_{1}, \theta_{2}\right)$ he chooses the action $\sigma^{*}(t)$.

We now verify that this manipulation satisfies the participation constraint and the incentive compatibility constraint on type space $\mathcal{T}^{\prime}$. This is a contradiction of the hypothesis that $(q, c, y)$ is implementable as a coalition-proof interim Nash equilibrium on type space $\mathcal{T}^{\prime}$.

To see that this manipulation is incentive compatible, note that under the manipulation individuals expect that the distribution of actions is with probability $\frac{1}{2}$ as if the true state was $\bar{s}^{\prime}$ and all individuals followed $\sigma^{*}$ and with probability $\frac{1}{2}$ as if the true state was $\bar{s}^{\prime \prime}$ and all individuals followed $\sigma^{*}$.

In either case, individuals get the same utility that they would get if they followed $\sigma^{*}$, taking the manipulated distribution of actions as given. This follows since, by assumption, $M$ implements $(q, c, y)$ on every complete information type space (equations (2)-(4) hold for every complete information types space with $s(\mathcal{T}) \in S$ ), individuals who differ only in their public goods preferences get the same utility from their $(c, y)$ bundle (equation (7)) and the manipulation is constructed such that an individual of type $t$ always chooses an action $\sigma^{*}(t)$ that is chosen by a type $t^{\prime}$ such that $w(t)=w\left(t^{\prime}\right)$. Hence, the manipulation is such that an individual's manipulated action is a best response. This implies incentive compatibility of the manipulation. The participation constraint is satisfied because each individual loses $\epsilon$ with probability $\frac{1}{2}$ and gains $2 \epsilon$ with probability $\frac{1}{2}$. Hence the expected utility gain from the manipulation is $\frac{1}{2} \epsilon>0$ for each individual.

\section{A.3 Proof of Proposition 3}

Step 1. We first establish the equivalence of statements (a) and (b). Obviously, (b) implies (a). Hence it remains to be shown that if a social function is implementable by some mechanism on every complete information type space, then it is also truthfully implementable on every complete information type space.

We limit attention to social choice functions that are individually incentive compatible. ${ }^{22}$ Suppose $(q, c, y)$ is individually incentive compatible and suppose that there is a complete information type space $\mathcal{T}^{\prime}$ with a cross-section distribution of payoff types equal to $s^{\prime}$ such that $(q, c, y)$ is not implementable as a truthful coalition-proof interim Nash equilibrium. Suppose without loss of generality that the direct mechanism deters any manipulation that is incompatible with the set $S$. Formally, let $\phi$ be a typical cross-section distribution of types and $\phi^{1}$ the corresponding marginal distribution of payoff types. We assume that distribution of types $\hat{\phi}$ that is communicated to the mechanism designer is such that $\hat{\phi}^{1} \in S .^{23}$

This implies in particular that we may assume that for all individuals who participate in a manipulation the skill levels are communicated truthfully to the overall mechanism, i.e., if $t$ is an individual's true type then the type $\hat{t}$ communicated to the overall mechanism is such that $w(t)=w(\hat{t})$ with probability 1 .

To see that this is without loss of generality, note that since all individuals on a complete

\footnotetext{
${ }^{22}$ Due to Proposition 1 if this property fails then a social choice function is not implementable by any mechanism. Also, as follows from the arguments in the proof of Proposition 1 if a social choice function is individually incentive compatible, then it is truthfully implementable as an interim Nash equilibrium on every complete information type spaces.

${ }^{23}$ If the failure of collective incentive compatibility was only due to a manipulation that induces an "off-the-equilibrium-outcome" then there is a direct mechanism that makes this outcome sufficiently unattractive and which implements the social choice function as a coalition-proof equilibrium.
} 
information type space have the same beliefs we may represent the subset of types $R$ who participate in a manipulation by a subset of skill levels and taste parameters $W_{R} \times \Theta_{R} \subset W \times \Theta$ so that $t \in R$ if and only if $(w(t), \theta(t)) \in W_{R} \times \Theta_{R}$. The assumptions that the manipulation induces a distribution of announcements with $\hat{\phi}^{1} \in S$ and that each $s \in S$ gives rise to the same marginal cross-section distribution $f$ of skill levels, ${ }^{24}$ imply that any effect that a false communication of payoff types for individuals with payoff types in $W_{R} \times \Theta_{R}$ may have on $\hat{\phi}^{1}$ can also be induced if all skill levels are communicated truthfully and only taste parameters are manipulated. ${ }^{25}$ Moreover, if only taste parameters are manipulated this implies that the manipulation is incentive compatible. This follows since individual incentive compatibility of the social choice function implies that individuals are willing to announce any taste parameter. Consequently, a manipulation is viable if and only if ist satisfies the participation constraint. By hypothesis $(q, c, y)$ is not implementable as a coalition-proof interim Nash equilibrium on $\mathcal{T}^{\prime}$. Hence there exists $R$ and a manipulation $\chi_{R}$ such that for all $t \in R$,

$$
\begin{gathered}
U\left(q\left(\hat{\phi}^{1}\right), c\left(\hat{\phi}^{1}, w(t)\right), y\left(\hat{\phi}^{1}, w(t)\right), w(t), \theta(t)\right) \\
>U\left(q\left(s^{\prime}\right), c\left(s^{\prime}, w(t)\right), y\left(s^{\prime}, w(t)\right), w(t), \theta(t)\right),
\end{gathered}
$$

where $\hat{\phi}^{1} \in S$ is the manipulated cross-section distribution of payoff types.

We show now that this implies that any mechanism that implements $(q, c, y)$ both on a complete information type space with payoff type distribution $s^{\prime}$ and on complete information type space with payoff type distribution $\hat{\phi}^{1}$ is not coalition-proof.

Let $M$ be a (non-direct) mechanism with an equilibrium strategy $\sigma^{*}$ that implements $(q, c, y)$ on the given complete information type space and on a complete information type space $\mathcal{T}^{\prime \prime}$ such that the cross-section distribution of payoff types equals $\hat{\phi}^{1}, s\left(\mathcal{T}^{\prime \prime}\right)=\hat{\phi}^{1}$. Now consider type space $\mathcal{T}^{\prime}$ and consider a manipulation $\chi_{R}^{\prime}$ which is defined with reference to the manipulation $\chi_{R}$ above: both manipulations have the same set of participating types $R$, and $\chi_{R}^{\prime}$ is constructed such that $\chi_{R}\left(\phi_{R}, t\right)\left[t^{\prime}\right]=\chi_{R}^{\prime}\left(\phi_{R}, t\right)\left[\sigma^{*}\left(t^{\prime}\right)\right]$ for all $\phi_{R}$, all $t \in R$ and all $t^{\prime} \in T$.

Given that $M=(A, Q, C, Y)$ implements the social choice function on $\mathcal{T}^{\prime}$ and on $\mathcal{T}^{\prime \prime}$ it must be true that for each $\mathcal{T} \in\left\{\mathcal{T}^{\prime}, \mathcal{T}^{\prime \prime}\right\}$,

$$
Q\left(\alpha\left(\phi(\mathcal{T}), \sigma^{*}\right)\right)=q(s(\mathcal{T}))
$$

and, for all $t$,

$$
C\left(\alpha\left(\phi(\mathcal{T}), \sigma^{*}\right), \sigma^{*}(t)\right)=c(s(\mathcal{T}), w(t), \theta(t))
$$

and

$$
Y\left(\alpha\left(\phi(\mathcal{T}), \sigma^{*}\right), \sigma^{*}(t)\right)=y(s(\mathcal{T}), w(t), \theta(t)) .
$$

Hence the payoff consequence from announcing some type $t \in R$ to the coalition organizer is the same under $M$ and under the direct mechanism. Also, the payoff consequence of announcing $t$ to the overall mechanism designer is the same as the payoff consequence of choosing action $\sigma^{*}(t)$ under the non-direct mechanism. This implies, in particular, that the manipulation $\chi_{R}^{\prime}$ is incentive compatible and satisfies the participation constraint.

\footnotetext{
${ }^{24}$ For each $s \in S$, and each $k \in\{1, \ldots, n\}, \sum_{l=1}^{m} s_{k l}=f_{k}$.

${ }^{25}$ More formally: Given a state $s$ and given that every individual with a payoff type $\left(w_{k}, \theta_{l}\right)$ that does not belong to $W_{R} \times \Theta_{R}$ reports truthfully, any $\hat{\phi}^{1}$ that the coalition organizer can induce if he only faces the constraint $\hat{\phi}^{1} \in S$ when choosing announcements for individuals with payoff types in $W_{R} \times \Theta_{R}$ can also be induced if the additional constraint, for all $t \in R$ the announcement $\hat{t}$ has to be such that $w(\hat{t})=w(t)$, is imposed.
} 
Step 2. We first show that (b) implies (c). Suppose that $(q, c, y)$ is individually incentive compatible and suppose that there is a complete information type space $\mathcal{T}^{\prime}$ with a cross-section distribution of payoff types equal to $s^{\prime}$ such that $(q, c, y)$ is not implementable as a truthful coalition-proof interim Nash equilibrium. We will show that this implies a violation of the collective incentive compatibility constraints.

Following the arguments in Step 1, we may assume $t \in R$ if and only if $(w(t), \theta(t)) \in W_{R} \times$ $\Theta_{R}$ and that skill levels are communicated truthfully and the inequality in (27) holds. This inequality may be equivalently stated as follows: There exists a subset $\Gamma_{R}$ of $\{1, \ldots, n\} \times$ $\{1, \ldots, m\}$ such that $(k, l) \in \Gamma_{R}$ implies that

$$
v\left(q\left(\hat{\phi}^{1}\right), \theta_{l}\right)+V_{k}\left(\hat{\phi}^{1}\right)>v\left(q\left(s^{\prime}\right), \theta_{l}\right)+V_{k}\left(s^{\prime}\right),
$$

for some $\hat{\phi}^{1} \in S$, where $\hat{\phi}^{1}$ belongs to the distribution of payoff types that can be induced if starting from $s^{\prime}$, for all types $\left(w_{k}, \theta_{l}\right),(k, l) \in \Gamma_{R}$, the probability mass $s_{k l}^{\prime}$ is reallocated among types $\left(w_{k}^{\prime}, \theta_{l}^{\prime}\right)$ such that $w_{k}=w_{k}^{\prime}$. This contradicts collective incentive compatibility.

We now show that (c) implies (b). Suppose that a social choice function is not collectively incentive compatible so that there is a state $s$ and a set $\Gamma$ and state $\hat{s} \in \hat{S}(s, \Gamma)$ such that for all $(k, l) \in \Gamma$,

$$
v\left(q(s), \theta_{l}\right)+V_{k}(s)<v\left(q(\hat{s}), \theta_{l}\right)+V_{k}(\hat{s})
$$

Now consider a direct mechanism that implements $(q, c, y)$ in a truthful interim Nash equilibrium on a complete information type space such that the distribution of payoff types is $s$ and on a complete information type space such that the distribution of payoff types is $\hat{s}$.

On the former type space, coalition-proofness fails: A manipulation for all types with payoff types $\left(w_{k}, \theta_{l}\right) \in \Gamma$ which involves only false announcements of taste parameters is incentive compatible provided the induced distribution of payoff types belongs to $S$. This follows from the facts that $(q, c, y)$ is individually incentive compatible and that individuals who differ only in their taste parameters receive the same $(c, y)$-bundle. By construction, there is a manipulation for individuals with types in $\Gamma$ that can induce the outcome $\hat{s}$. By (32) this makes all of them better off, so that the participation constraint is also satisfied.

\section{A.4 Side payments and Collective Incentive Compatibility}

In this section we show that the notion of collective incentive compatibility that was derived in Proposition 3 does not rely on the assumption that coalition formation must not be facilitated by the use of side payments. We proceed in two steps. We first fix an arbitrary type space and define implementability of a social choice function as a "coalition-proof equilibrium interim Nash equilibrium with side payments" on this type space. Second, we require that implementation is possible on every complete information type space and derive a notion of "collective incentive compatibility with side payments". In particular, it will become clear that "collective incentive compatibility with side payments" is the same as "collective incentive compatibility without side payments."

We now consider the possibility that individuals make a (possibly negative) payment to the coalition organizer. An individual's payment to the coalition organizer reduces his after tax income, or, equivalently, his private goods consumption. The coalition organizer is not a source of funds, so that the aggregate payment has to be non-negative. However, the coalition organizer may redistribute side payments among different types of individuals.

Given a mechanism $M=(A, Q, C, Y)$, a manipulation with side payments for individuals with types in $R$ is a list of probability distributions $\chi_{R}=\left\{\chi_{R}\left(\phi_{R}, t\right)\right\}_{t \in R}$ with support $A$ as in 
Section 3.2, and in addition a payment scheme $\rho_{R}=\left\{\rho_{R}\left(\phi_{R}, t\right)\right\}_{t \in R}$ where $\rho_{R}\left(\phi_{R}, t\right)$ is the side payment of an individual who has announced type $t$ to the coalition manager.

We denote by

$$
\begin{aligned}
& \tilde{U}\left(\alpha\left(\phi, \sigma, \chi_{R}\right), a, p, w(t), \theta(t)\right) \\
& :=U\left(Q\left(\left(\alpha\left(\phi, \sigma, \chi_{R}\right)\right), C\left(\alpha\left(\phi, \sigma, \chi_{R}\right)\right), a\right)-p, Y\left(\alpha\left(\phi, \sigma, \chi_{R}\right), a\right), w(t), \theta(t)\right)
\end{aligned}
$$

the utility that a type $t$ individual realizes under mechanism $M$ from choosing action $a$ and delivering side payment $p$ given that the distribution of actions is $\alpha\left(\phi, \sigma, \chi_{R}\right)$.

Given a type space $\mathcal{T}$ a mechanism $M$ and an interim Nash equilibrium strategy $\sigma^{*}$, we say that manipulation $\left(\chi_{R}, \rho_{R}\right)$ satisfies the participation constraint, if for all $t \in R$,

$$
\begin{aligned}
\int_{\Delta_{T}} \int_{A} \tilde{U}\left(\alpha\left(\phi(\mathcal{T}), \sigma, \chi_{R}\right), a, \rho_{R}\left(\phi_{R}(\mathcal{T}), t\right), w(t), \theta(t)\right) d \chi_{R}\left(\phi_{R}(\mathcal{T}), t\right) d \pi(t) \\
>\int_{\Delta_{T}} \tilde{U}\left(\alpha\left(\phi(\mathcal{T}), \sigma^{*}\right), \sigma^{*}(t), w(t), \theta(t)\right) d \pi(t) .
\end{aligned}
$$

Also, a manipulation has to satisfy the following incentive compatibility constraints. First, for all $t \in R$ and all $t^{\prime} \in R$,

$$
\begin{aligned}
& \int_{\Delta_{T}} \int_{A} \tilde{U}\left(\alpha\left(\phi(\mathcal{T}), \sigma, \chi_{R}\right), a, \rho_{R}\left(\phi_{R}(\mathcal{T}), t\right), w(t), \theta(t)\right) d \chi_{R}\left(\phi_{R}(\mathcal{T}), t\right) d \pi(t) \\
\geq & \int_{\Delta_{T}} \int_{A} \tilde{U}\left(\alpha\left(\phi(\mathcal{T}), \sigma, \chi_{R}\right), a, \rho_{R}\left(\phi_{R}(\mathcal{T}), t^{\prime}\right), w(t), \theta(t)\right) d \chi_{R}\left(\phi_{R}(\mathcal{T}), t^{\prime}\right) d \pi(t) .
\end{aligned}
$$

Second, for every $t \in R$ and every $a^{\prime} \in A$,

$$
\begin{array}{r}
\int_{\Delta_{T}} \int_{A} \tilde{U}\left(\alpha\left(\phi(\mathcal{T}), \sigma, \chi_{R}\right), a, \rho_{R}\left(\phi_{R}(\mathcal{T}), t\right), w(t), \theta(t)\right) d \chi_{R}\left(\phi_{R}(\mathcal{T}), t\right) d \pi(t) \\
\geq \int_{\Delta_{T}} \tilde{U}\left(\alpha\left(\phi(\mathcal{T}), \sigma, \chi_{R}\right), a^{\prime}, w(t), \theta(t)\right) d \pi(t) .
\end{array}
$$

Finally, a manipulation has to be budgetary feasible on the given type space, i.e., it must be true that

$$
\int_{R} \phi_{R}\left(\phi_{R}(\mathcal{T}), t\right) d \phi_{R}(\mathcal{T}) \geq 0
$$

$\sigma^{*}$ is said to be a coalition-proof interim Nash equilibrium with side payments in the game induced by mechanism $M$ on type space $\mathcal{T}$ if it is an interim Nash equilibrium and there is no subset of types $R$ with a manipulation $\left(\chi_{R}, \rho_{R}\right)$ that is incentive compatible, budgetary feasible and satisfies the participation constraint. We are interested in characterizing the social choice functions that can be implemented as a coalition-proof interim Nash equilibrium with side payments on every complete information type space.

For notational ease we limit attention to direct mechanisms and to truthful equilibria. Let $(q, c, y)$ be an individually incentive compatible social choice function, so that, by Proposition $1,(q, c, y)$ can be truthfully implemented as an interim Nash equilibrium on each complete information type space.

We now show the following: any manipulation that is incentive compatible, budgetary feasible and satisfies the participation constraint on some complete information type space has zero side payments.

To see this, consider a complete information type space $\mathcal{T}$ with a cross-section distribution of preferences equal to $s$. Suppose there is manipulation for types in $R$ that induces the outcome intended for some other complete information type space $\mathcal{T}^{\prime}$ with distribution $s^{\prime}$. By (35), (34) 
and the fact that $(q, c, y)$ is individually incentive compatible, manipulating individuals must get at least the payoff that they would get from announcing their types truthfully to the overall mechanism, taking as given that the distribution of announcements indicates that the state of the economy is $s^{\prime}$ : for all $t \in R$,

$$
\begin{array}{r}
\int_{T}\left\{v\left(q\left(s^{\prime}\right), \theta(t)\right)+u\left(c\left(s^{\prime}, w\left(t^{\prime}\right)\right)-\rho_{R}(\cdot, t), y\left(s^{\prime}, w\left(t^{\prime}\right)\right), w(t)\right)\right\} d \chi_{R}(\cdot, t) \\
\geq v\left(q\left(s^{\prime}\right), \theta(t)\right)+u\left(c\left(s^{\prime}, w(t)\right), y\left(s^{\prime}, w(t)\right), w(t)\right),
\end{array}
$$

where $t^{\prime}$ is the type announced by the coalition organizer to the overall mechanism on behalf of an individual with type $t$ according to probability distribution $\chi_{R}(\cdot, t)$. Equivalently (37) may be written as

$$
\begin{array}{r}
\int_{T}\left\{u\left(c\left(s^{\prime}, w\left(t^{\prime}\right)\right)-\rho_{R}(\cdot, t), y\left(s^{\prime}, w\left(t^{\prime}\right)\right), w(t)\right)\right\} d \chi_{R}(\cdot, t) \\
\geq u\left(c\left(s^{\prime}, w(t)\right), y\left(s^{\prime}, w(t)\right), w(t)\right),
\end{array}
$$

This inequality holds only if there exists $t^{\prime}$ such that

$$
u\left(c\left(s^{\prime}, w\left(t^{\prime}\right)\right)-\rho_{R}(\cdot, t), y\left(s^{\prime}, w\left(t^{\prime}\right)\right), w(t)\right) \geq u\left(c\left(s^{\prime}, w(t)\right), y\left(s^{\prime}, w(t)\right), w(t)\right)
$$

By individual incentive compatibility

$$
u\left(c\left(s^{\prime}, w(t)\right), y\left(s^{\prime}, w(t)\right), w(t)\right) \geq u\left(c\left(s^{\prime}, w\left(t^{\prime}\right)\right), y\left(s^{\prime}, w\left(t^{\prime}\right)\right), w(t)\right) .
$$

Combining (40) and (39) yields $\rho_{R}(\cdot, t) \leq 0$. This implies that all individuals who participate in the manipulation make non-negative side payments. Combining this with the manipulation's resource constraint implies that for (almost) all deviating types side payments have to be equal to zero.

The interpretation of this observation is straightforward. In principle, allowing for side payments extends the set of manipulations that are potentially viable. However, in a large economy, no individual is pivotal for the success of a manipulation which affects the cross-section distribution of announcements to the overall mechanism. Individuals can therefore enjoy the outcome of a manipulation without contributing any positive side payment. Consequently, individuals will participate only if this involves no personal cost. This implies that side payments can not be used.

\section{A.5 Proof of Proposition 4}

The constraints in (14) trivially imply that the inequalities (16) and (15) hold. For instance, if (15) was violated and the true state of the economy was $s=\left(s_{k}^{l}, s_{-k}\right)$, individuals whose taste parameter equals $\theta_{l}$ would collectively lie about their taste parameters and induce an announced distribution $\hat{s}_{k}=s_{k}^{l+1}$.

We now want to show that the inequalities (16) and (15) imply that the constraints in (14) are satisfied. First note that for given $k, s_{-k}$ and $l$, adding the inequalities (15) and (16), where the latter is formulated for $l+1$ instead of $l$, yields

$$
v\left(q\left(s_{k}^{l+1}, s_{-k}\right), \theta_{l+1}\right)-v\left(q\left(s_{k}^{l}, s_{-k}\right), \theta_{l+1}\right) \geq v\left(q\left(s_{k}^{l+1}, s_{-k}\right), \theta_{l}\right)-v\left(q\left(s_{k}^{l}, s_{-k}\right), \theta_{l}\right)
$$

Using the assumption that $v_{q}(q, \theta)$ is, for every given $q \in \mathbb{R}$, increasing in $\theta$ makes it possible to show that

$$
q\left(s_{k}^{l+1}, s_{-k}\right), \theta_{l+1} \geq q\left(s_{k}^{l}, s_{-k}\right) .
$$


Second, suppose that the true state of the economy is $\left(s_{k}^{l}, s_{-k}\right)$. Then any manipulation of individuals with $w^{i}=w_{k}$ requires the participation of those with $\theta^{i}=\theta_{l}$. If those individuals do not participate and reveal their characteristics truthfully, any alternative manipulation in state $\left(s_{k}^{l}, s_{-k}\right)$ would induce a result that is incompatible with $S_{k}$.

Third, the inequalities (16) and (15) exclude that individuals with $\theta^{i}=\theta_{l}$ participate in a "local deviation", i.e., a manipulation that induces the outcome for state $\left(s_{k}^{l+1}, s_{-k}\right)$ or state $\left(s_{k}^{l-1}, s_{-k}\right)$. It remains to be shown that these individuals do also refuse participation for any other manipulation.

Consider a manipulation that attempts to induce the outcome for state $\left(s_{k}^{l+j}, s_{-k}\right)$ for some $j>1$. We want to show that

$$
v\left(q\left(s_{k}^{l}, s_{-k}\right), \theta_{l}\right)+V_{k}\left(s_{k}^{l}, s_{-k}\right) \geq v\left(q\left(s_{k}^{l+j}, s_{-k}\right), \theta_{l}\right)+V_{k}\left(s_{k}^{l+j}, s_{-k}\right) .
$$

The monotonicity of $q$, (see the inequality in (41)) and the assumption $v_{q}(q, \theta)$ is increasing in $\theta$, have the following implication: The local incentive constraint

$$
v\left(q\left(s_{k}^{l+j-1}, s_{-k}\right), \theta_{l+j-1}\right)+V_{k}\left(s_{k}^{l+j-1}, s_{-k}\right) \geq v\left(q\left(s_{k}^{l+j}, s_{-k}\right), \theta_{l+j-i}\right)+V_{k}\left(s_{k}^{l+j}, s_{-k}\right) .
$$

implies that for all $g \leq l+j-1$,

$$
v\left(q\left(s_{k}^{l+j-1}, s_{-k}\right), \theta_{g}\right)+V_{k}\left(s_{k}^{l+j-1}, s_{-k}\right) \geq v\left(q\left(s_{k}^{l+j}, s_{-k}\right), \theta_{g}\right)+V_{k}\left(s_{k}^{l+j}, s_{-k}\right) .
$$

A repeated application of this argument implies that

$$
\begin{aligned}
v\left(q\left(s_{k}^{l}, s_{-k}\right), \theta_{l}\right)+V_{k}\left(s_{k}^{l}, s_{-k}\right) & \geq v\left(q\left(s_{k}^{l+1}, s_{-k}\right), \theta_{l}\right)+V_{k}\left(s_{k}^{l+1}, s_{-k}\right) \\
& \geq v\left(q\left(s_{k}^{l+2}, s_{-k}\right), \theta_{l}\right)+V_{k}\left(s_{k}^{l+2}, s_{-k}\right) \\
& \geq \ldots
\end{aligned}
$$

which establishes (42). A symmetric argument can be used to show that

$$
v\left(q\left(s_{k}^{l}, s_{-k}\right), \theta_{l}\right)+V_{k}\left(s_{k}^{l}, s_{-k}\right) \geq v\left(q\left(s_{k}^{l-j}, s_{-k}\right), \theta_{l}\right)+V_{k}\left(s_{k}^{l-j}, s_{-k}\right),
$$

for all $j>1$. 


\section{Preprints 2008}

218. Carsten Burhop / Thorsten Lübbers: Incentives and Innovation? R\&D Management in Germany’s High-Tech Industries During the Second Industrial Revolution. 2008/38.

217. Andreas Nicklisch / Tobias Salz: Reciprocity and status in a virtual field experiment. 2008/37.

216. Andreas Glöckner / Christoph Engel: Can We Trust Intuitive Jurors? An Experimental Analysis. 2008/36.

215. Jörn Lüdemann: Wettbewerb und Regulierung in der Telekommunikation. Das Telekommunikationsrecht vor den Herausforderungen dynamischer Märkte. 2008/35.

published in:

Jörn Lüdemann (Hrsg.), Telekommunikation, Energie, Eisenbahn - Welche Regulierung brauchen die Netzwirtschaften? Tübingen (Mohr Siebeck) 2008, S. 69-99

214. Martin Beckenkamp: Playing strategically against nature? - Decisions viewed from a game-theoretic frame. 2008/34.

213. Christoph Engel: Preponderance of the Evidence versus Intime Conviction. A Behavioural Perspective on a Conflict between American and Continental European Law? 2008/33.

212. Kristoffel Grechenig: Schadenersatz bei Verletzung von $\S 14 \mathrm{WpHG}$ ? Insiderhandel mit positiver und negativer Information. 2008/32.

211. Felix Bierbrauer: Optimal Income Taxation, Public Goods Provision and Robust Mechanism Design. 2008/31.

210. Hans-Theo Normann: Vertical Integration, Raising Rivals' Costs and Upstream Collusion. 2008/30.

forthcoming in:

European Economic Review

209. Martin Hellwig: Competition Policy and Sector-Specific Regulation for Network Industries. 2008/29.

forthcoming in:

X. Vives (ed.), "Competition Policy in the EU: Fifty Years on from the Treaty of Rome" Oxford University Press.

208. Niels Petersen: Rational Choice or Deliberation? - Customary International Law between Coordination and Constitutionalization. 2008/28.

207. Stephen Broadberry / Carsten Burhop: Resolving the Anglo-German Industrial Productivity Puzzle, 1895-1935:

A Response to Professor Ritschl. 2008/27.

forthcoming in:

Journal of Economic History

206. Niels Petersen: Demokratie und Grundgesetz - Veränderungen des Demokratieprinzips in Art. 20 Abs. 2 GG angesichts der Herausforderungen moderner Staatlichkeit. 2008/26.

205. Andreas Nicklisch: Semi-collusive advertising and pricing in experimental duopolies. 2008/25.

204. Andreas Nicklisch: Inequity Aversion, Reciprocity, and Appropriateness in the Ultimatum-Revenge Game. 2008/24.

203. Christoph Engel: The Behaviour of Corporate Actors. A Survey of the Empirical Literature. 2008/23.

202. Emanuel Vahid Towfigh: Komplexität und Normenklarheit - oder: Gesetze sind für Juristen gemacht. 2008/22.

201. Christian Traxler / Andreas Reutter: Apportionment, Fiscal Equalization and Decentralized Tax Enforcement. 2008/21.

200. Christoph Engel, REITs ante portas. Die Anpassung des deutschen Rechts an institutionelle Investoren in den Grundstücks- und Mietmärkten. 2008/20.

forthcoming in:

Juristenzeitung

199. Christoph Engel, Ernst-Joachim Mestmäcker. 2008/19.

forthcoming in:

Stefan Grundmann / Karl Riesenhuber (eds.): Deutschsprachige Zivilrechtslehrer des 20. Jahrhunderts in Berichten ihrer Schüler, Band 2, Berlin (De Gruyter) 
198. Andreas Glöckner, „Neurorecht“ ohne Psychologie? Die Rolle verhaltenswissenschaftlicher Betrachtungsebenen bei der Ableitung rechtspolitischer Empfehlungen. 2008/18.

forthcoming in:

S. Schleim, T. M. Spranger \& H. Walter (Eds.), Von der Neuroethik zum Neurorecht? Göttingen: Vandenhoeck \& Ruprecht.

197. Ernesto Crivelli/Klaas Staal, Size, Spillovers and Soft Budget Constraints. 2008/17.

196. Niels Petersen, The Principle of Democratic Teleology in International Law. 2008/16.

195. Markus Quirin/Martin Beckenkamp/Julius Kuhl, Giving or Taking: The Role of Dispositional Power Motivation and Positive Affect in Profit Maximization. 2008/15.

194. Andreas Glöckner/Tilmann Betsch/Nicola Schindler, Construction of Probabilistic Inferences by Constraint Satisfaction. 2008/14.

193. Carsten Burhop/Thorsten Lübbers, Cartels, managerial incentives, and productive efficiency in German coal mining, 1881-1913. 2008/13.

192. Andreas Glöckner/Tilmann Betsch, Multiple-Reason Decision Making Based on Automatic Processing. 2008/12. forthcoming in:

Journal of Experimental Psychology: Learning, Memory, and Cognition

191. Christian Bayer/Carsten Burhop, Corporate Governance and Incentive Contracts: Historical Evidence from a Legal Reform. 2008/11.

190. Hendrik Hakenes/Martin Peitz, Umbrella Branding and External Certification. 2008/10.

189. Felix Bierbrauer / Marco Sahm, Optimal Democratic Mechanisms for Taxation and Public Good Provision. 2008/9.

188. Andreas Glöckner, How Evolution Outwits Bounded Rationality. The Efficient Interaction of Automatic and Deliberate Processes in Decision Making and Implications for Institutions. 2008/8.

forthcoming in:

C. Engel \& W. Singer (Eds.), Better Than Conscious? Implications for Performance and Institutional Analysis. Strüngmann Forum Report 1. Cambridge, MA: MIT Press.

187. Remi Maier-Rigaud: International Organizations as Corporate Actors: Agency and Emergence in Theories of International Relations. 2008/7.

186. Stephan Lauermann, Price Setting in a Decentralized Market and the Competitive Outcome. 2008/6.

185. Andreas Glöckner / Tilmann Betsch, Do People Make Decisions Under Risk Based on Ignorance? An Empirical Test of the Priority Heuristic against Cumulative Prospect Theory. 2008/5.

forthcoming in:

Organizational Behavior and Human Decision Processes

184. Martin Hellwig, A Maximum Principle for Control Problems with Monotonicity Constraints. 2008/4.

183. Carsten Burhop, Pharmaceutical research in Wilhelmine Germany: The case of E. Merck. 2008/3.

182. Andreas Glöckner / Tilmann Betsch, Modeling Option and Strategy Choices with Connectionist Networks: Towards an Integrative Model of Automatic and Deliberate Decision Making? 2008/2.

forthcoming in:

Judgment and Decision Making

181. Christa Hainz / Hendrik Hakenes, The Politician and his Banker. 2008/1. 